CALLING ALL ISSUERS:

THE MARKET FOR DEBT MONITORING

Huaizhi Chen

Lauren Cohen

Weiling Liu

WORKING PAPER 29790 
NBER WORKING PAPER SERIES

\title{
CALLING ALL ISSUERS: \\ THE MARKET FOR DEBT MONITORING
}

\author{
Huaizhi Chen \\ Lauren Cohen \\ Weiling Liu \\ Working Paper 29790 \\ http://www.nber.org/papers/w29790 \\ NATIONAL BUREAU OF ECONOMIC RESEARCH \\ 1050 Massachusetts Avenue \\ Cambridge, MA 02138
}

February 2022, Revised October 2022

We would like to thank David Abel (Columbia Capital Management), Rajesh Aggarwal, Emily Brock (Director, Federal Liaison Center of the Government Finance Officers Association), John Campbell, Julia Cooper (Director of Finance, City of San José), Zhi Da, Daniel Garrett, Tiantian $\mathrm{Gu}$, Michael Loguercio (Munistat), Andrew Kalotay (Andrew Kalotay Associates), Francis Longstaff, Dermott Murphy, Giang Nyguyen, Peter Orr (Intuitive Analytics), Michael Pacella (Assistant Superintendent for Business at Pine Bush Central School District), Richard Ryffel (First Bank), Sophie Shive, and seminar participants at the Municipal Finance Workshop, University of Notre Dame, Northeastern University, Western Finance Association, Brooking's Municipal Finance Conference, and the Fixed Income and Financial Institutions Conference for helpful comments and suggestions. We also thank Yixuan $\mathrm{Li}$ for providing valuable research assistance. The views expressed herein are those of the authors and do not necessarily reflect the views of the National Bureau of Economic Research.

NBER working papers are circulated for discussion and comment purposes. They have not been peer-reviewed or been subject to the review by the NBER Board of Directors that accompanies official NBER publications.

(C) 2022 by Huaizhi Chen, Lauren Cohen, and Weiling Liu. All rights reserved. Short sections of text, not to exceed two paragraphs, may be quoted without explicit permission provided that full credit, including $\odot$ notice, is given to the source. 
Calling All Issuers: The Market for Debt Monitoring

Huaizhi Chen, Lauren Cohen, and Weiling Liu

NBER Working Paper No. 29790

February 2022, Revised October 2022

JEL No. G18,G21,G24,G28,G32,G38,H7,H74

\begin{abstract}
95\% of long-term municipal bonds have callable features, and yet we find new evidence of a substantial fraction of local governments exercising these valuable options sub-optimally, with significant delays - resulting in sizable losses. Using data from 2001 to 2018, we estimate that U.S. municipals lost over $\$ 26$ billion from delayed refinancing, whereas the entire U.S. corporate sector, facing the same low interest-rate environment, lost only a comparatively modest $\$ 1.4$ billion. We present evidence that these delays are related to gaps in localized debt monitoring. For instance, when a bond's call unlocks in a month that is the fiscal year-end of a local government - a particularly busy time for finance departments - the decision to call is delayed significantly longer. A significantly longer delay also occurs when a municipality is faced with waves of calls all coming due at once. These effects are magnified in smaller municipalities, staffed with smaller finance departments. Moreover, the market for outside monitoring (e.g., underwriters), is a fractured one. It is characterized by extreme stickiness: $87 \%$ of a municipality's bonds are issued with the same underwriter over our sample period. The usage of a less locally-focused underwriter is associated with significantly greater delays.
\end{abstract}

\author{
Huaizhi Chen \\ University of Notre Dame \\ hchen11@nd.edu \\ Lauren Cohen \\ Harvard Business School \\ Baker Library 273 \\ Soldiers Field \\ Boston, MA 02163 \\ and NBER \\ lcohen@hbs.edu
}

Weiling Liu

414F Hayden Hall

238 Mendoza College of Business

Northeastern University

Boston, MA 02115

w.liu@northeastern.edu 


\section{Introduction}

When the majority of securities are issued, their subsequent value is determined by the underlying asset's evolution, market pricing, or payment functions. However, certain securities are issued embedded with options that allow the issuers or holders to "unlock" future value depending on certain states of the world. The realization of this value often depends on both the state of the world occurring and an explicit action taken by the option-holder. In this paper, we provide novel evidence that one of the largest debt markets in the world - the US Municipal Bond Market - suffers from significant lapses in these exact actions. These lapses result in losses in the tens of billions of dollars to the towns and cities issuing them, ultimately falling on the taxpayers to offset. We show using micro-level data that oversights across the monitoring chain of these markets aggregate to produce the dynamics we document.

Namely, between 2001 and 2018, we find that although the vast majority of municipal bonds contain a call feature (nearly 95\%), refinancing mistakes lead to large value losses - ultimately falling on taxpayers around the country. Take for example, a $\$ 47.1$ million borrowing by Rio Hondo Community College District in California undertaken in November 3, 2005 to help pay for capital improvements. $\$ 38.9$ million of these were current interest bonds that could be called at par any time after August 1, 2015, but they were only called more than four years later on June 21, 2019. The cumulative value lost to Rio Hondo district residents from these four years of delay by the financing office is estimated to be $\$ 2.69$ million - equal to a $6.4 \%$ one-time increase in personal property taxes in the year of call. ${ }^{1}$ To put this in context, that cost would be more than double the maximum allowable statutory threshold in California - with the maximum allowable tax increase set at $2 \%$ for assessed property values under Proposition 13.

We find this pattern across the universe of municipals spanning time, location, credit rating, and bond-issue size - with municipals failing to call their bonds in a timely manner, even after their bonds have become callable, resulting in a significant value loss

\footnotetext{
${ }^{1}$ Most education municipal bonds are repaid through personal property tax revenues. The main cities covered in the Rio Hondo Community College district include Whittier, Pico Rivera, Santa Fe Springs, El Monte, and South El Monte. Based upon their public city budgets for FY 2018-2019, we estimate that they collected a total of $\$ 41.7$ million in personal property taxes.
} 
to their municipalities. We estimate that, between January 1, 2001 and December 31, 2018, $\$ 1.38$ billion USD was lost annually in the municipal market by issuers due to late calls. Over our sample period, this amounts to a total of $\$ 26.2$ billion USD, even after accounting for estimates of issuance fees and other transaction costs. This is in stark contrast to delays in the corporate bond market, where we estimate a comparably modest loss of less than $5 \%$ the size (only roughly $\$ 78$ million per year). ${ }^{2}$

While we find the delays to be widespread, we do identify cross-sectional variation in delays within and across bond issue sizes, municipal issuer sizes, geographic locations, sample periods, bond structures, bond purposes, and credit ratings. We demonstrate that these patterns of delays are consistent with issuer inattentiveness. In particular, we relate issuer workloads to indicators of redemption delays. Bonds are less likely to be called at their issuer's fiscal year-end and when their issuer has an unusually large number of other bonds to consider refinancing at the same time.

While competitive underwriters serving this market could serve as external monitors substituting for issuer inattentiveness, we find varying evidence for them doing so. In particular, those underwriters most geographically-focused and specialized empirically appear to be best at monitoring and avoiding these costly delays for their client municipalities.

We begin our analysis by characterizing bonds in the municipal market at the time when they first become callable- i.e., at their call unlock date. We find that municipal bonds tend to have coupon rates fixed at around 5\% and call prices fixed at principal value $^{3}$. In contrast, the average yield at issuance for municipal bonds fell substantially below the coupon rates over our sample. For example, the offering yields to maturity were as low as $1.5 \%$ in 2019 for AAA-rated bonds. The combination of par redemption value,

\footnotetext{
${ }^{2}$ During our sample period, corporate bonds are often issued with Make-Whole Call provisions, which require the issuer to pay both the fixed principal amount and a variable discounted value of all future coupons, severely limiting the impact of the call option itself. These provisions are much less often used by municipal bond issuers- less than $2 \%$ of our sample. Moreover, contrasting studies of the corporate bond market in the 70s and 80s (e.g. King and Mauer (2000); Longstaff and Tuckman (1994); Kraus (1993); Mauer (1993); and Fischer, Heinkel, and Zechner (1989)), in the most recent time periods, we find corporate bonds with fixed call prices tend not to lose value by delaying calls (see Appendix C).

${ }^{3}$ More than $73 \%$ of our bond sample never have a call price above par; and $99 \%$ of our sample never have a call price that goes above 102. In Table A3, we explain delay behavior controlling for the maximum call price, and while bonds with call price above par are unsurprisingly more likely to delay, our main findings remain unchanged.
} 
fixed coupon payments, and lower offering yields implies that there are substantial issuer savings to be gained through refinancing as soon as these bonds unlock and become callable.

We assess the economic magnitude of the redemption delays parametrically using the American Option pricing framework of Longstaff and Schwartz (2001). For simplicity, we embed a Merton single factor model of short rate dynamics in our primary specification. However, our results are quantitatively similar when we use a multifactor interest rate setting (see Appendix B). With the sample of solely investment grade callable bonds, we estimate the value lost from call-delays to be $\$ 1.74$ billion dollars per year between 2001 and 2018 (over $\$ 31$ billion dollars in total). We also conduct an analogous estimation exercise using corporate bonds over the same sample period and find a significantly lower magnitude of less than $5 \%$ this value (roughly $\$ 78$ million per annum).

We next move to uncovering the factors associated with the municipalities, monitors, bond issues, and timing of call delays across geographies that might help to explain the observed variation in the decision to delay bond calls. First, we consider a set of basic bond characteristics, controlling for: state, year, bond type, and initial rating fixed effects. We find that bonds are significantly more likely to experience delays in redemptions if they: i.) receive a credit downgrade, ii.) have more time remaining until maturity, iii.) have a smaller issuance size, iv.) pay smaller coupons, or v.) have lower offering yield. However, even after controlling for these bond characteristics and fixed effects, there is still substantial unexplained variation in calling delays; the R-squared from the full specification regression explaining delays is 19\%. Motivated by these persistent and systematic (still-unexplained) delays, we then explore other factors that appear most associated with the municipal issuers and monitors involved in the redemption decisions.

We first consider the role of issuers' internal resource constraints. To concretize this, many of the offices responsible for municipal finance at the local level are modestly staffed, and their employees often wear multiple hats within the broader city/town/municipality office. ${ }^{4}$ Perhaps as a result, the average issuer takes seven months

\footnotetext{
${ }^{4}$ We would like to again thank the many municipalities, underwriters, advisors, and government agency representatives for their incredibly helpful conversations and experiences in understanding the nuances and dynamics of this market in detail (included in the acknowledgement section).
} 
to call a bond after it has unlocked its call-option. Supporting the issuer constraint hypothesis, we find that an issuer who faces heavier workloads, defined as having more bonds that are callable in a year than their average over the last five years, takes significantly longer to redeem their existing debt. Moreover, these delays are also significantly longer when the call unlocks during fiscal year ends. These are the precise times that the financial groups within many local governments in particular face tighter time constraints, as they prepare to submit the municipalities' annual budgets. ${ }^{5}$ Consistent with workload-driven inattentiveness, we find that general obligation bonds that become callable during the month of the fiscal year end are delayed by an additional 2.4 months $(\mathrm{t}=4.32)$. Serving as a placebo test, in contrast, revenue bonds - whose signing authorities are not a local government (e.g., Yankee Stadium), and so are not tied to taxpayer funding or follow the same fiscal calendar - do not exhibit these year-end patterns.

As mentioned, financial underwriters are key monitors in the municipal market, as they specialize in bond valuation and can earn commissions by refinancing callable bonds. While issuer-underwriter relationships can change - stemming from either side of the matching decision and re-optimizing with a new issuer/underwriter - empirically, we find that the underwriter-issuer relationship is remarkably sticky. On average, over our sample, an issuer uses the same lead underwriter for $87 \%$ of its bonds. Moreover, we find that an issuer who remains in the same "sticky" underwriter relationship at the time their bond becomes unlocked is 7.5 percentage points more likely to delay calling than an issuer who has switched its underwriter since the issuance.

We then move on to explore the industrial organization of underwriter-issuer relationships by region. In particular, while there are certain underwriters with a large presence across the United States (e.g., Citibank, JP Morgan, and Merrill Lynch), we find that many other underwriters have specific geographic concentrations - being very active and competitive in some regions, while essentially non-existent in others. One example of this is Dougherty \& Company LLC, which has written over $\$ 5.2$ billion USD of municipal bonds in North and South Dakota but does not have a strong market share in

\footnotetext{
${ }^{5}$ We would like to thank Julia Cooper, Director of Finance for the City of San José, in particular, for the suggestion that fiscal calendars and workload causes calling delays at some offices, especially for smaller issuers.
} 
any other state. We then explore the localized focus of an issuer's chosen lead underwriter by comparing the relative issuance activity of the lead underwriter compared to the most active underwriter in the state. To test whether this location-specific investment in resources matters, in our finest identification, we look within underwriter (for the same underwriter, e.g. Citibank, we compare states in which it dedicates a large amount of resources vs. states on which it focuses relatively fewer resources) and find that a one standard deviation higher local focus (vs. one standard deviation lower) is associated with a bond that is 12 percent $(\mathrm{t}=6.49)$ less likely to delay. Interestingly, this local concentration effect can be somewhat offset when the overall market is deep and competitive; for instance, local attentiveness has a more modest effect on delays for the three largest state markets (CA, TX, and NY), while its importance to reduce bond delays is magnified twice as strongly in all other states.

Besides underwriter and issuers, there are other agents in the market for municipal debt monitoring of local governments. The most central of these external agents in this market are Municipal Financial Advisors - taking the role of advisor to municipalities regarding issuance, re-issuance, calling, terms, underwriter choice, etc. ${ }^{6}$ We find that the relationship between the municipality and financial advisor - much like that with the underwriter - is empirically very sticky over time, and exhibits regional focus. However, the use of a financial advisor by a municipality does not seem to substantially alleviate (or correlate with) the calling delays we observe in the data ${ }^{7}$.

Ultimately, the decision to refinance is a crucial one for both individual borrowers as well as institutions. To our knowledge, we are the first to document the substantial value destroyed by security issuers who delay the decision to utilize refinancing options. Moreover, we present evidence of an imperfect market for monitoring of these securities. Further exploration into the surprisingly sticky underwriter-issuer relationships, their genesis, reinforcing equilibria (including the role of municipal advisors), along with the

\footnotetext{
${ }^{6}$ Specialized municipal-finance legal counsel are additional external agents utilized by most municipalities. They commonly advise on issues including tax-efficiency, ongoing disclosure, and other considerations surrounding issuance and reissuance. However, from our conversations with municipalities and advisors, they do not commonly take a large role in advising the specific decision to call.

${ }^{7}$ Furthermore, we find no differential effect of advising on delays post Rule-23 (enacted in 2011), which prohibits underwriters from also acting as municipal bond advisors. However, it is possible that Rule G-23 made both advisers and underwriters more diligent. Consistent with this interpretation, all else held equal, we find that bonds are less likely to delay overall post 2011 .
} 
full range of their implications for states', cities', hospitals', public-works' and all other municipal issuers' quantities and rates of financing has first-order implications for the financial markets.

The remainder of the paper is organized as follows. Section II of the paper provides a brief background and literature review, and Section III discusses our data sources on bonds, municipalities, and other agents in more detail. Section III then presents our central findings on municipal delay behavior, while Section IV explores both the impacts of the behavior along with novel mechanisms and outside debt monitoring. Finally, Section $\mathrm{V}$ concludes.

\section{Literature}

Our paper relates to several streams of literature. First, with regard to public finance, we document a powerful new debt refinancing channel of inefficiency that has substantive implications for state and local governments. Past works have examined bonds that engage in advanced refundings as spurred by short-comings in municipal cash-flows. For example, Ang, Green, Longstaff, and Xing (2017) find that financially constrained municipals are likely to refund their debt before the bond's call option unlocks (i.e. employing an advanced refunding) and a substantial number of these advance refundings occur at a net present value loss. This follows other works on advanced refundings (Dammon and Spatt (1993), Kalotay and May (1998), and Kalotay and Abreo (2010)). Additionally, Butler, Fauver, and Mortal (2009); Gao, Murphy, and Qi (2019b); and Nakhmurina (2020) demonstrate that bond market outcomes are key factors in municipal governance. Other examinations of municipal market inefficiencies include Garrett (2021), which studies dual advisors; Cornaggia, Hund, and Nguyen (2020), which studies bond insurance; and Dagostino (2018), which studies bank financing.

We complement this prior work by exploring a new channel - showing that a significant number of municipals delay in the utilization of bond call options after their respective unlocks (i.e. employing a current refunding), and this results in substantial implied losses across the municipal finance market. The municipal bonds that drive this loss are well represented across time, issuer size, bond size, geography, bond structure, 
and funding purpose - and in recent times comprise a much larger set of bonds. We utilize these samples to give insight into how underwriter relationship in the municipal securities market affect an issuer's ability to effectively manage finances.

This issuer monitoring channel ties our study to a literature on security issuances in the financial markets. Altinkilic and Hansen (2000) and Yasuda (2005) examine underwriters and their respective issuance fees of corporate bonds. A line of research including Hansen and Torregrosa (1992), Ritter and Welch (2002), Ljungqvist, Jenkinson, and Wilhem (2003), and Drucker and Puri (2005) investigate the interactions between investment bank underwriters and their corporate clients. Additional evidence from Burch, Nanda, and Warther (2005) show that there are substantial costs for issuers that switch from existing underwriter relationships. Fernando, May, and Megginson (2012) examine the collapse of Lehman Brothers on their respective corporate investment banking relationships.

In calculating the potential value lost by bond issuers in delaying the call decision, we follow a large literature that studies the valuation of bonds' call options. In the corporate bond market, these works extend as far back as Ingersoll (1977), which focuses on convertible bonds, and $\mathrm{Vu}$ (1986), which focuses on non-convertible bonds. More recently, other examples include King (2002), Jarrow et al. (2010), and Jacoby and Shiller (2010). In the callable Treasury bond market, notable works include Longstaff (1992), which finds a puzzling negative call price; Jordan et al (1995), which explains the puzzle using an alternative pricing model; and Bliss and Ronn (1998), which explains the puzzle using pricing distortions such as the 120-day call notification period. Our work utilizes and extends these valuation techniques to the public municipal bond market to analyze the imperfect relationship between debt underwriters and issuers.

Lastly, we add to a set of papers that specifically seeks to understand refinancing decisions by agents. There is a substantial literature on personal debt refinancing from interest rate fluctuations. For example, Agarwal, Amromin, Ben-David, Chomsisengphet, Piskorski, and Seru (2017) and Defusco and Mondragon (2020) investigate channels that prevent agents from optimally refinancing mortgage debt. In the corporate market, Becker, Campello, Thell, and Yan (2018) show that longer maturity and lower quality bonds are more likely to be issued with a callable feature. Specific to the municipal market, studies using a limited subset of available bond issues highlight the unique factors that 
drive bond issuances. These examples include political considerations (Vijayakumar, 1995) and issuer characteristics (Moldogaziev and Luby, 2012). In contrast to these previous case studies of the municipal market, we utilize the most comprehensive set of U.S. bonds outstanding between 2000 and 2018. To our knowledge, we are the first paper to quantify the large and economically substantial value lost through delays spanning the universe of publicly traded municipal securities, along with underwriters' roles in monitoring these call-option delays.

\section{Municipal Bond Characteristic Data, Call Data, Pricing Data, Ratings Data and Financial Agent Data}

Our main dataset comes from Mergent's Municipal Bond database, which covers the majority of municipal bonds outstanding and includes bonds dating back to the 1800s. For each bond, we observe issuance information including issuer, state, coupon, par value, issuing yield, maturity date, project type, dated date, as well as information on the underwriters and advisors. For each bond, we also observe the date in which the call option was unlocked and if it was either partially or fully redeemed at specific redemption dates.

The coverage of the Mergent data on the US municipal issuance market is comprehensive. We compared the aggregate value of bonds outstanding from Mergent against the Securities Industry and Financial Markets Association's annual report, and confirm that the two-time series have essentially congruent magnitudes and total coverage. We also verify the calling status of bonds in Mergent against Bloomberg for all bonds with over $\$ 1.5$ million USD of par value outstanding. If the bond was reported to have been called in Bloomberg but not in Mergent, then we supplement the Mergent data with Bloomberg information on both the call date and called amount. ${ }^{8}$

\footnotetext{
${ }^{8}$ For the remaining bonds that are smaller than $\$ 1.5 \mathrm{mil}$ in par value, there may be some discrepancies between Mergent and Bloomberg calling data. Using 1,000 bonds randomly drawn from this subsample, we found more bonds (90 vs 30 bonds) which were not called according to Bloomberg but were called according to Mergent, compared to the reverse- not called according to Mergent but called according to Bloomberg. Overall, Mergent appears to be a more reliable data source. To check that the choice of data source does not ultimately affect our key findings, we also try removing all uncalled bonds in the Mergent data with par value under $\$ 1.5 \mathrm{mil}$, which were reported to be called in Bloomberg. When we repeat our baseline regression analysis in Table A10, we find that our results are nearly identical.
} 
Our main analysis is conducted on the set of long term (with maturities of at least 10 years) callable bonds whose call options were unlocked between January 1, 2001 and December 31, 2018. In order to have a uniform sample, we remove all bonds that had a super sinker provision, defaulted, or were issued in one of the following territories: Puerto Rico, Virgin Islands, Guam, and Detroit. Furthermore, in order to keep the call decision straightforward, we remove bonds that were issued with variable rates, make whole provisions, as well as put options. We drop very small bonds (CUSIP level) with par amounts less than 150,000 USD, and we only keep bonds that had credit ratings within a year of their issuance. ${ }^{9}$ Finally, in our main regressions that look at the decision to delay calling a bond after its call option has unlocked, we exclude the set of bonds which have already been called prior to the call unlock date. Our final sample covers 211,942 unique bonds and 22,921 unique issuers. Table 1 summarizes key characteristics of our main sample. From Table 1, in our sample bonds on average have an offering price of $\$ 99.82$, a coupon rate of $4.95 \%$, and an offer size of $\$ 3.21$ million.

Finally, our bond credit ratings come from Standard \& Poor's Capital IQ database. For each bond in our main sample, we obtain the rating at the time of issuance as well as at the time when the call option was unlocked. If a rating is missing at the time of a bond's issuance, we use the rating from within one-year of the bond's issuance date.

\section{Main Results: Significant Evidence of Calling Days Across the Municipal Bond Universe}

\section{IV.1 Delays in Calling}

\section{IV.1.1 Aggregate Trends}

Between 2001 and 2018, we find that a large fraction of callable municipal bonds delay redemption- waiting at least one year after their call option unlocks to call. Figure 1 illustrates the total par value of currently callable bonds (blue line) and the portion of these bonds that still did not call by the end of the year (orange line). We see that while aggregate total dollar bond volume has been generally trending up since 2001 (from

\footnotetext{
${ }^{9}$ Regression results are identical if we include these unrated bonds, variable rates, etc. as separate dummy categories, as these niche bond-type issuances empirically comprise a small percentage of the universe.
} 
around $\$ 20$ billion to over $\$ 70$ billion in 2018), it has declined since its peaks in the financial crisis in 2008-2009. This said, the uncalled-portion remains a sizable majority of the portion-value throughout the sample up through present-day. In 2018, for instance, roughly $\$ 71$ billion USD of municipal bonds had call features which were unlocked, and over $70 \%$ of these bonds did not exercise their call options within the following year. This delay in calling behavior is thus a systematic one throughout time and aggregate market conditions.

While a large portion of municipal bonds do not call over our sample, this is not typical of all bond markets. As a benchmark in Figure 2, we show the estimated call-value lost from municipal bonds (blue line) compared to corporate bonds (orange line). We see that, despite the fact that the corporate bond market is actually of much larger size than the municipal market (and that over half of corporate bonds (and rising) also contain callable features), there is comparatively significantly less value lost due to any delay in calling behavior over the same period in the corporate bond market (operating in the same economic and interest rate environment). This is consistent with a different behavioral disposition regarding the timeliness of exercising the valuable option to call between corporate vs. municipal issuers. One possible explanation for the differences between these two markets is the sophistication of issuers and the underwriters that advise on calling decisions; we explore this hypothesis in more depth in Section IV.3.

Over our data sample period of 2001-2018, several market conditions made it optimal for municipal issuers to redeem and refinance outstanding bonds. While the ongoing offering yields declined for all segments of credit ratings in the municipal debt market, the coupon rates of the existing callable debts remained fixed at a $5 \%$ average. Thus, the gap between the existing and refinancing yields continued to widen and (and so become more attractive) over time. Figure 3 shows the coupon rate at issuance (Panel A) and the remaining number of years to maturity at time of unlock (Panel B). We see that the average coupon rates centers at 5\% with most coupon rates falling between $4 \%$ and $6 \%$. In addition, Panel $\mathrm{B}$ shows that unlocked bonds had considerable numbers of years left to maturity - ranging up to 30 years- implying that there could be a considerable premium obtainable through the reissuance of these debts.

For refinancing to be optimal, bond yields must be low enough to offset future coupon payments. In Figure 4, we show the offering yield of bonds offered between 2001 Calling All Issuers - 10 
and 2019 over different credit rating buckets. While lower rated bonds naturally have higher yields to compensate for their credit risk, we see that yields are low relative to the average 5\% coupon rates and have generally trended downwards across all bond ratings. For example, while AAA bonds have offering yields of roughly $4.2 \%$ in 2001 , by 2019 , the same types of bonds had yields of $1.7 \%$ at issuance. This implies that there has been a sizable and rising premium obtainable issuers that choose to refinance existing bonds with new issues.

\section{IV.1.2 Comparison to Advance Refunding}

It is important to distinguish between refunding prior to the call unlock date (an advance refunding) versus calling after the call option has unlocked (a current refunding). Delays to current refunding coexist with but are separate from advance refundings, which are synthetic early calls and are another key feature of the municipal market, especially prior to 2018 when tax-exempt advance refundings was eliminated by The Tax Cuts and Jobs Act of $2017 .{ }^{10}$ The set of advance refunded bonds and bonds with calling delays are mutually exclusive. Since advance refunded bonds must call at the original bond's first call date, their calls can never be delayed by definition. Therefore, when we analyze the decision to delay calling, we (by construction) exclude bonds that have already been advance refunded, and all of our results are thus empirically distinct from advance refundings.

That said, we explore and compare the two phenomena in order to understand their potential relationships in the data. Issuers that advance refund tend to look different from those that call with delays. They are attentive to interest rates and seek to benefit from reduced cash outflows (Ang et al. 2017). In contrast, we find that issuers that delay calling appear to be less attentive to financial opportunities and are more reliant on external financial agents (Section IV.3).

The overwhelming majority of issuers fit into one of two categories: they tend to either call bonds with a delay or use advance refundings - the correlation between percent

\footnotetext{
${ }^{10}$ Figure A1 shows the annual par amount of advance refunded bonds over time, and we see that there is a steep drop in recent years beginning in 2018 due to the tax reform. While municipal bonds can still be advance refunded into taxable bonds, these are less attractive to some investors given their less favorable tax treatment following the 2017 Act, and thus, less attractive to municipals as well. Moreover, comparing the aggregate sizes of annual par amounts of advance refunded bonds versus call-delayed bonds over our comparative sample period (2001-2018, Figures 1 and A1), they are roughly equivalent in terms of total aggregate area under the curve (par amount sizes) over the period.
} 
of advance refundings and percent delays within an issuer in our sample is large and highly negatively significant at $-70 \%$. In Tables 5 and A2, we show bonds which are advance refunded have characteristics which are generally the opposite of bonds that delay calling. For example, they tend to have larger coupons and have larger par amounts than bonds that delay their redemptions. Interestingly, there are is a small set of issuers who appear to neither advance refund nor delay, suggesting that they may be more sophisticated than other issuers. This subset includes state level housing authorities. For example, over our sample, Virginia State Housing Development Authority issued 385 bonds total and only about $7 \%$ of them used advance refunding or delayed a call. This may be because they are a large, established agency with over 300 staff and have a lot of experience, having been in business since 1972 .

\section{IV.1.3 Variation Across and Within States, Bond Types, and Credit Ratings}

In this section, we document how calling delays vary both across and within a number of observable bond characteristics. In particular, we show that the delays in redemption exist both across and within three different dimensions: state of issue, bond type, and credit rating. While issuers across categories differ in their promptness to redeem (bonds issued in California tend to have longer wait times to redemption than bonds issued in Connecticut), there is substantial variation that exists within each of these categories (within both Connecticut and California, we side wide variation in the calling behavior across municipalities).

Table 2 summarizes the propensity to redeem bonds across states, sorted by the size of each state's total municipal bonds outstanding. California, New York, and Texas have the largest amount of bonds outstanding at $\$ 344.6, \$ 324.8$, and $\$ 232.0$ billion, respectively. We observe a substantial fraction of issued bonds that delay calling a year or more after they become redeemable (Column 4) and a sizable percentage of outstanding bonds that never redeem prior to maturity (Column 5). Figure 5 visually depicts this variation across states. Panel A depicts the percent of issued bonds that were at least oneyear after they are redeemable by each state. While states like California, Arkansas, and Rhode Island delay more than $30 \%$ of their callable bonds, states like Utah, Hawaii, and Connecticut delay less than half that percentage - roughly $12 \%$ of their bonds. In Panel $\mathrm{B}$, we show the percent of callable bonds that were never redeemed prior to maturity. For 
instance, Massachusetts experiences this for roughly $18 \%$ of their bonds, while Delaware never call only roughly $6 \%$ of their bonds.

Next, we find that there is variation in the decision to call across the funding sources of municipal bonds. Table 3 shows that $52 \%$ of bonds that were funded through special taxes experienced redemption delays, while fuel/vehicle tax-linked bonds had less than a third of that delay rate, at only 16\% delayed. Interestingly, General Obligation (GO) bonds, despite having the safest and lowest default probability, still had roughly $18 \%$ of bonds with delays of one year or more. In fact, roughly $11 \%$ of GO bonds with call options unlocked between 2009 and 2018 never call.

Finally, Table 4 summarizes the delay in calling by each bond's credit rating at the time when the call option unlocked. ${ }^{11}$ We see that there is a general pattern that lower rated bonds are delayed significantly more often than higher rated bonds. However, the lion's share of issuance in the municipal market is seen in higher rated bonds (A, AA, and AAA) as seen in Column 1 of Table 4. Moreover, even despite the high credit quality of these buckets, over $25 \%$ of bonds with the highest rated AAA bonds delayed their redemptions by one year or more, for instance. Furthermore, nearly $10 \%$ of these AAA bonds were never called by their issuers prior to maturity ${ }^{12}$.

\section{IV.2 Calculating Value Lost from Delay}

\section{IV.2.1 Understanding the Decision to Call}

In this section, we will quantitatively estimate the potential values gained and lost in delays due to redemption exercises ${ }^{13}$. As well understood in the bond pricing literature

\footnotetext{
${ }^{11}$ While we do not consider them for our main analyses, summaries for unrated bonds can also be found for comparison in Table A4. In addition, if we break down the rating categories by whether the bond was downgraded prior to the call unlock date, we find that downgraded bonds are more slightly likely to delay. However, downgrades do not explain much variation in calling delays. In general, for bonds with contemporaneous ratings of BBB or higher, the likelihood of delay is similar for downgraded and nondowngraded bonds.

${ }^{12}$ It is important to consider the role of insurance when looking at ratings. AAA bonds are more likely to be insured and insurance may be costly to purchase for the new bond. However, this is unlikely to drive our key results for two reasons: first, AAA-rated bonds represent a small portion of our sample; and second, a large portion of our bonds unlocked post-financial crisis, in which the muni insurance market was much more costly and generally unlikely to be a consideration for a new bond issue.

${ }^{13}$ It could be that the initial call option purchase, which over $95 \%$ of long-term bonds make in recent years, is also a mistake. However, if this is the primary mistake, then we would not expect to find all of the correlations with end-of-year, size of staff, underwriter dependence, which we show extensively in Section IV.4.
} 
(Ingersoll, 1977), a callable bond grants its issuer an American call option on a noncallable but otherwise identical bond. The value lost from not redeeming a bond therefore can be calculated as the deviation from the optimal exercise of this American option. See Appendix B for a detailed review of this optimal exercise problem.

\section{IV.2.2 Valuing the Call Option}

We estimate the value of a bond's embedded American call option using the simulated option valuation techniques from Longstaff and Schwartz (2001), and approximate the value lost through delays as the expected change in the option value due to non-exercise.

To start, at any given time, we specify a risk neutral dynamic for the market municipal short-term interest rate. In our baseline results, we assume that the short-term municipal rate is described by a one factor Merton model: the short-term interest rate follows random walk with a bound at zero, an annualized volatility of 33 basis points ${ }^{14}$, and has an initial rate matched to the prevailing market issuance rates for short-term bonds of similar risks. ${ }^{15}$ (See Appendix B for a detailed description and alternative shortrate model specifications). With this simple calibration, we then estimate both the immediate exercise value of the American call option and the present value of this option from non-exercise. Optimally, the issuer should redeem the bond whenever the immediate exercise value is higher than the expected non-exercise value of the option. When an issuer violates this optimal stopping rule by delaying to redeem, we estimate the value lost as the difference between the immediate exercise value and the expected non-exercise value of the bond's call option.

\section{IV.2.3 Estimating Empirical Values}

We calculate the total value lost from delays to exercise by calibrating across the entire panel of callable bonds outstanding each year. For computational tractability, we group bonds into bins matched by coupon rates (every 10 basis points), prevailing market short-term rates (every 10 basis points) for bonds of similar credit ratings, and the number

\footnotetext{
14 This choice of volatility exceeds the physical standard deviation experienced by muni yields in the past 10 years. The semi-annual realized standard deviation of ten-year muni yields was about 30 basis per every 6 months. The options-implied volatility from the newly callable bonds is about 10 to 20 basis points.

${ }^{15}$ We can also match the issuance rates to bonds within the same state. Although this method generates a higher likelihood of missing comparable issuance rates, the aggregate results are qualitatively similar.
} 
of coupon payment periods. ${ }^{16}$ Using the aforementioned Merton one factor model, we estimate the optimal exercise value for each bin and the cost of delaying to exercise (every 6 months). Finally, we sum the cost of delayed exercise for all callable bonds per year with investment grade credit ratings from $\mathrm{S} \& \mathrm{P}$.

We find that the value lost from not exercising call options between 2001 and 2018 is large and economically meaningful. In Figure 2, we plot the dollar value estimated loss from the delay to exercise. The annual value lost is shown in blue - the calculated value lost begins at $\$ 0.23$ billion dollars per year in 2001 and then rises to as high as $\$ 2.1$ billion per year in 2012. ${ }^{17}$

To benchmark the estimated costs in the municipal market, we also plot a similar dollar value estimate of corporate bonds in orange over the identical period, using similarly calibrated volatility and coupon rates. We estimate a significantly lower magnitude for value lost in corporate bonds. These two estimates together indicate that the variation in delays are specific to the municipal bond market. ${ }^{18}$

\section{IV.3 Explaining Variation in Delay Behavior}

Thus far, we have found that across the universe of municipal bonds, a sizable percentage delay their optional redemptions or do not redeem at all prior to maturity, which is generally suboptimal behavior given the interest rate environment over our sample period. Moreover, we observe substantial variation in calling behavior across

\footnotetext{
${ }^{16}$ For computational simplicity, we approximate all bonds as having semi-annual paying coupons. While it is possible to discretize even more finely, the delay value-lost calculation is simply the net gain of reissuing the bond cash-flows (without accumulated interest) immediately versus waiting another 6-months.

${ }^{17}$ The loss values shown in Figure 2 are shown using an estimated issuance cost of $1.02 \%$ of par, which is the national empirical average muni bond issuance cost found in Joffe (2015). We show in Figure A2 that our results are not materially affected if we assume a range of fees from $0 \%$ up to $5 \%$ of par. This is perhaps not surprising, because as long as the bond is eventually called, the issuance costs have to be paid and their only cost impact is the time-value of delay. Given that delayed (but eventually called) bonds make up over half of our sample, they represent the majority of our value loss estimates. Finally, to address the concern that bonds in our sample may differ from previous studies along key dimensions, such as the size of the issuer, we estimate a hedonic fee model based upon public issuance data published by the state of California (summary statistics shown in Table A5, and hedonic model shown in Table A6). When this cost model is fitted to our muni sample, the estimated average cost is $0.93 \%$. We would like to thank Marc Joffe for pointing us to this dataset.

${ }_{18}$ Two additional considerations for municipals when calling include voter approval and the notice period. Unlike new issuances, GO refundings do not require public voter approval, and thus, there are no monetary or time costs incurred for a bond campaign. In addition, for most municipals, the notice period for calling a bond is 30 days; this is not long enough to explain our observed delays of at least than one year.
} 
states, bond types, and credit ratings. In this section, we explore whether there are factors systematically related to the bonds, times, and agents involved in its issuance that can explain this delayed redemption behavior.

We use the following regression specification: ${ }^{19}$

$$
\operatorname{Delay}_{i, s, t}=\alpha+\mu_{s}+\gamma_{t}+\beta X_{i, s, t}+\epsilon_{i, s, t}
$$

where Delay $_{i, s, t}$ is an indicator for a delay of one year or more after bond $i$ has unlocked in state $s$ and year $t ; \mu_{s}$ and $\gamma_{t}$ refer to state and year fixed effects respectively; and $X_{i, s, t}$ is a vector of characteristics including: bond traits, proxies for issuer workload constraints, underwriter characteristics, and the persistence in relationship between a bond's issuer and its underwriter.

\section{IV.3.1 Explaining Delays using Baseline Bond Characteristics}

Table 5 begins by examining how the propensity to delay redemptions is related to an initial set of observable traits of the municipal bond, including a number of fixed effects. Explanatory variables include: a dummy for whether the bond was downgraded prior to its unlock date, remaining days-to-maturity after unlock, log size of issuance, coupon rate, and offering yield. In these baseline regressions, we then also include: state fixed effects, project type fixed effects, and initial credit rating fixed effects, along with year of unlock fixed effects: so the estimates in Table 5 can be interpreted as the variation in observed delay behavior that the independent variables are related within all of these categories. Since advance refunded bonds have already been called before the call option unlocks, they are excluded from our sample.

From Table 5, we observe that delays are positively related to both credit downgrades (even controlling for initial credit rating) and remaining months-to-maturity, while being negatively related to the size of the issuance, coupon rates, and offering yield. In considering the interpretation of these estimates, Column 1 thus implies that when coupon rates being currently paid are higher (all else held equal), issuers benefit relatively more from refinancing, and we therefore see that this is negatively related to delays. Next, from Column 2, issuers with higher offering yields are more likely to call their bonds in a

\footnotetext{
${ }^{19}$ We find that the results are robust and consistent using different specification models - such as Probit which we show in comparison to our baseline regression specification (Table 5) in Table A1.
} 
timely manner, consistent with Column $1^{20}$. When a bond is downgraded over its life, the issuer experiences credit-deterioration and is thus likely to face higher yields at refinancing. As shown in Column 3, it is then not surprising that bonds with downgrades are $8.8 \%$ more likely to delay calling. In Column 4 , the coefficient on days-to-maturity is positive, suggesting that issuers are more likely to delay if they have a longer period over which they can call in the future. Finally, in Column 5, the size of the bond issuance is negatively related to delays. ${ }^{21}$

In the last Column of Table 5, we add all the baseline explanatory variables simultaneously. The cumulative R-squared of the regression rises to $19 \%$, yet this still indicates a substantial degree of unexplained variation in the decision to promptly refinance municipal bonds across the universe of municipalities over time ${ }^{22}$. Thus, taken together, we find that while several traits of municipal bond issuances - including their coupon rates and offering sizes - are associated with calling delays, even after accounting for these baseline traits, there remains significant variation in the final decision to promptly call outstanding bonds.

In the next section, we explore potential mechanisms that could explain calling delays: the roles of issuer workload and attentiveness along with variation in the scope of external-agent debt monitoring.

\section{IV.4 What is Driving Delays? The Roles of Workload, Attentiveness, and Debt Monitoring}

IV.4.1 Issuer Workload and Attentiveness

IV.4.1.1 Fiscal Year-Ends

\footnotetext{
${ }^{20}$ Conversely, this suggests that delayed bonds, on average, have 3.9 bps lower yields (column 6 ) -roughly $0.7 \%$ of the average yield of 5pps. This implies market investors can partially but imperfectly guess which bonds are more likely to delay calling in advance, and thus, offer higher prices or lower yields.

${ }^{21}$ In Table A2, we compare the traits of delayed bonds versus those of advance refunded bonds by using a dummy for advanced refunding as the left-hand side variable. Comparing Tables 5 and A2, the characteristics of advance refunded bonds are exactly opposite to those of delayed bonds, and consistent with more attentive behavior to maximize near-term cash positions.

22 While we do not know the maximum possible R-squared for our model, we know there is still considerable unexplained variation, because if we just add issuer fixed effects, the R-squared more than triples to $62 \%$.
} 
Over our sample period, issuers on average redeem a bond seven months after the bond becomes callable. A typical redemption transaction takes time and effort to process. At a minimum, an evaluation of market rates and some financial calculus are necessary in order to understand whether and when a bond should be called. As bonds are typically refunded through a new offering, it will take effort to decide how to structure the refunding bond. If an issuer were perfectly attentive, they could begin this in anticipation of the perfectly known-in-advance call date and redeem promptly at the optimal post-call unlocking date. However, if an issuer were relatively less attentive (due to internal or external constraints), they might be slower to promptly exercise their redemption options, even when optimal.

For many local governments, the end of their state's fiscal calendar coincides with heightened workloads and lower attentiveness to outstanding issues. This is especially true for the budgetary departments, given their central role in the preparation, aggregation, processing, and revision of annual municipal budgets across each division into the municipal-wide fiscal budget. If it is not costless to temporarily modulate the size of its staff month-by-month to accommodate both expected and unexpected work-flow shocks, then the budgetary departments might face less time (on average, all-else-equal) to attend to other activities. Fiscal authorities may thus be less timely in evaluating bond redemptions, and this may especially be true for smaller municipals with tighter staffing.

We test this possible variation in issuer workload constraint in Table 6. Namely, in Column 1, we regress the average wait time between the unlock date and the day the bond is called on Fiscal calendar dummies. Month before FY End, FY End, and Month after FY End are dummy variables equal to one if the month that the bond's call option unlocked was the month before its state's fiscal year end, the month of the fiscal year end, or the month after the fiscal year end, respectively. We find that, controlling for other bond characteristics and fixed effects, bonds that are unlocked at fiscal year-end are on average delayed by an additional 2.4 months $(\mathrm{t}=4.32)$. This is consistent with a limited workload constraint channel of debt refinancing.

In Columns 2 and 3 of Table 6, we explore whether smaller issuers, presumably with less staff and financial expertise, might be even more adversely affected by fiscal year end deadlines. In these specifications, we include a dummy for small issuer, which is defined as one if it issued fewer than five bond issues total over our sample period. We 
interact this dummy with the fiscal year-end indicators and show this full specification in Column 3.

First, in Column 2, small issuers on average take significantly longer than others to call their bonds (when Dummy for Small Issuer is included in a stand-alone categorical variable specification). Then exploring more deeply in Column 3, we see two additional patterns. Combining the main effects from the top 3 rows with their respective interaction terms in Rows 4-7, we see: i.) small issuers experience a strong and prolonged additional delay starting from the month before fiscal year end (Coefficient on the interaction term of Small * Month before FY End of $0.604(t=2.25))$; and ii.) that this delay is not "reversed" or somehow unraveled in the surrounding months vis-à-vis larger issuers, as the small issuers again experience slightly longer delays in point-estimate in these months (though statistically insignificantly so - FY End coefficient $+S_{\text {Small }}^{*} F Y$ End coefficient, and Month after FY End coefficient + Small*Month after FY End coefficient, respectively).

Finally, in Column 4, we conduct a falsification test using revenue bonds. Revenue bonds - unlike most general obligation municipal bonds - are not governed by the local government but by the board of the project itself (e.g., hospital, road, nursing home facility). Thus, on average, they are much less likely to follow the state's fiscal cycle. As an example, consider a revenue bond from our sample in which the issuer was the Port Authority of NY and NJ. It is the Port Authority Board of Commissioners listed at the end of the bond issuance document and they are the ones who decide to call. Rather than following New York's fiscal year, which ends March 31, the Port Authority has a fiscal year that ends on December 31, as reflected in its annual budget as well as the bond's financial operating filings. Thus, we would not expect this bond to follow New York State's fiscal cycle but rather that of its issuing entity.

The results of this sample-wide falsification test are reported in Column 4 of Table 6. We find no significant effect of local government fiscal calendars (e.g., New York State's fiscal year end) on calling delays for these revenue bonds (e.g., the Port Authority of NY and NJ revenue bond).

IV.4.1.2 Workload Shocks due to Abnormal Unlocked Volume 
Depending on factors such as local budgets and ballot outcomes, municipal bond issuances can be lumpy and multiple bonds can have their redemption options unlocked in certain years for certain investors (while other years have none). The coincidence of many bonds unlocking at once may lead to resource-constraints in local attention for the issuer- the unlocking dates are often determined a decade or more in the past coinciding with the terms of the original issuance. We show that these spikes in workload result in more calling delays - similar to the fiscal year-end result patterns in Table 6 - and again consistent with constraints due to issuer workload intensity ${ }^{23}$.

The results are shown in Table 7. From Table 7, for our panel of municipal bonds, we regress how likely each bond is to experience a calling delay on a proxy of abnormal workloads experienced by its municipality. In Column 1, for each bond, we define its issuer's workload as the difference between the number of unlocked bonds and the average number of unlocked bonds the issuer had to consider over the past five years. When this difference is larger, an issuer experiences larger than usual workload, indicating a potential constraint in resources and workload. If an issuer did not have any bonds unlock over the last five years, then the bond is dropped from our sample. We find that controlling for other bond characteristics, for each standard deviation increase in issuer workload (3.5 bonds unlocked), the bond experiences 0.8 month of additional delay time $(t=3.77)$. This effect on delays is especially strong in Column 3 for the subsample of historically less busy and less experienced issuers (defined as those who have had less than five issues unlock over the last five years - i.e., less than one per year on average): for each standard deviation increase in issuer workload, the bond experiences 1.7 months of additional delays $(\mathrm{t}=4.27)$. These results, together with the findings in Table 6, support the hypothesis that an issuer's ability to process workload is constrained and thus, issuers may not always be able to call right away.

In Columns 2 and 4, we further break down the main explanatory regressor (Prev Num Issues Unlocked - $5 \mathrm{y}$ Avg of Num Issues Unlocked) into its two separate components:

\footnotetext{
${ }^{23}$ One factor which is related to both workload as well as staff size is subsidies for smaller issuers-the primary one being bank qualification. We examine this factor closely and find that bank-qualification is unlikely to be driving our main results. First, bank qualified issuers make up than less than one-third (31\%) of our sample. Furthermore, if we remove them and just look at the larger, non-bank qualified issuers, we find consistent (similar size and same significance) results for both workload and FY end tables. These results are shown in Tables A8 and A9.
} 
Num Issues Unlocked and Prev $5 y$ Avg of Num Issues Unlocked, respectively. We find that both work, and significantly so, in the directions one might expect. Issuers delay significantly more unconditionally when they are inundated with a large number of unlocks in a given year, and those with more general experience in unlocking bonds exhibit this delay behavior significantly less often. Moreover, from Column 4, both of these behavioral effects appear to impact less experienced issuer departments more (e.g., being suddenly inundated with many unlocks, and the incremental benefit of getting more experience).

In sum, we document that constraints to local issuer resources and workload using variation in the timing of fiscal year ends and current workloads, along with size and experience of the issuing departments - can significantly delay the promptness of the redemption behavior across the municipal bond market. The sum of the evidence is consistent with an internal resource constraint channel - when an issuer has limited ability and resources to attend to and process workloads, it is more likely to exhibit delays in calling.

\section{IV.4.2 Debt Monitoring and the Role of Underwriters}

Given the results in prior sections regarding call delays, one might ask why outside agents have not stepped in to reduce workload costs, and otherwise rectify this behavior. In the municipal markets, outside underwriters in particular play a critical role in the decision to finance debt. Principally, these players are incentivized to monitor the outstanding bonds in order to participate in potential refinances, where they will earn commission through the underwriting fee of new issues. In this subsection, we will consider how these key market monitors imperfectly alleviate redemption delays.

We begin by exploring the basic industrial organization of municipal underwriting. Empirically, underwriters vary substantially in terms of size as well as geographic concentration. As a demonstration, in Figure 6, we highlight the geographic resource allocation amongst three medium to large municipal underwriters in the United States: Citigroup, Morgan Keegan, and Dougherty \& Company LLC.). Locally Focused is calculated as the total amount underwritten in each state by the given underwriter divided by the total amount underwritten by the largest underwriter in the state between years 2001 and 2018. This variable thus ranges between 0 (the firm does not underwrite at all 
in given state) to 1 (the firm is the top underwriter in the given state). For example, if Morgan Keegan was the largest underwriter in Tennessee, it would have a locally focused ratio of 1 . In contrast, if it did not underwrite at all in Tennessee, it would have a locally focused ratio of $0^{24}$.

As Figure 6 shows, Citigroup (Panel A) - a representative large national underwriter - writes bonds throughout the country, but can be seen to be especially relatively resource-heavy in certain regions, such as on the East and West Coasts. In contrast, medium sized firms like Morgan Keegan and Dougherty concentrate their resources much more narrowly - being equally dominant, but in this smaller set of chosen markets. In particular, Morgan Keegan is dominant in parts of the South, while Dougherty is heavily focused specifically on solely North and South Dakota. Figure 6 then highlights the varying geographical segmentation that characterizes municipal finance underwriting markets. Moreover, it brings up the possibility that having an underwriter specialized (concentrated) on your specific region - such as the debt underwritten by Dougherty in the Dakotas - might differ in some ways than having a large national underwriter in those regions.

To explore this local underwriter resource concentration in more detail, we explore the relationship in Table 8. Since the raw ratio is characterized by a heavy left tail (i.e., the market is top heavy and the largest underwriters often write orders of magnitude more than the smallest), we then transform it by taking its natural log. In order to help interpret the coefficients, we also standardize this log ratio so that it has mean 0 and standard deviation of 1 . From Table 8 , we find evidence that bonds underwritten by locally concentrating underwriters are significantly less likely to experience delay in their redemption schedule ${ }^{25}$. First, in Column 1 of Table 8, we regress a dummy for a bond with a calling delay of greater than one year on the local resource concentration of the bond's

\footnotetext{
${ }^{24}$ This is only in theory. In practice, no underwriters have a value of 0 , since they are only in the data if they underwrote at least one bond.

${ }^{25}$ Recently, Cestau (2020) showed that the industrial organization of the underwriter market includes factors such as the type of bid. To test whether this may drive our findings, in Table A7, we additionally control for negotiated vs competitive bids. The effect of locally focused becomes slightly weaker, but overall, we still find consistent (size and significance) results. Finally, while some issuers may also choose to use private placements and this is becoming more popular lately, this is unlikely to affect our results since private placements make up only $0.15 \%$ of our sample.
} 
lead underwriter (Locally Focused). Consistent with local debt monitoring being valuable, we find that bonds using a locally focused underwriter are significantly less likely to experience delays in calling. The coefficient in Column 1 of $-0.0155(t=14.76)$ suggests that an issuer utilizing a locally focused underwriter who is one standard deviation above the mean in terms of local resource allocation will experience a roughly $14 \%$ reduction in calling delay probability relative to an underwriter one standard deviation below. ${ }^{26}$

Interestingly, we find that it is not the overall national size of the underwriter but rather the relative local resource focus of the underwriter in the given market that matters. In Column 2 of Table 8, we add underwriter fixed effects, and we continue to find a substantive negative, significant coefficient on local resource concentration. These results indicate that even if two bonds used the same underwriter, such as Citigroup, the bond which is located in a state where Citigroup is relatively more focused (one standard deviation above) would be roughly $12 \%$ ( $t=6.76$ ) less likely to delay than a bond located in a state that Citigroup is less focused (one standard deviation below).

In addition to the localized focus of the underwriter, in Columns 3-5 we find additional evidence for the market structure being associated with calling delays. In particular, in Column 3 we find that choosing the "right" states to utilize More Geographically Spread Underwriters (e.g., national underwriters such Citibank) is more critical for monitoring relative to underwriters who already solely focus on a narrow set of select states. In Columns 4 and 5, we then find that this local concentration effect can be somewhat offset when the overall market is deep and competitive. From Table 8, for instance, local resource focus has a more modest effect on delays for the three largest state markets (CA, TX, and NY) (Column 5), while its importance to reduce bond delays is magnified twice as strongly in all other states (Column 4).

\section{IV.4.3 Persistence in Underwriter and Issuer Relationships}

While some underwriters appear less active in monitoring their issuers than others, ultimately, issuers choose their agents - and whether to stay with them - always having the option to switch underwriters. Relatedly, underwriters themselves are open to actively

${ }^{26}$ This $14 \%$ comes from a $3.1 \%(1.55+1.55)$ decrease relative to the unconditional mean of $21.9 \%(3.1 / 21.9)$. 
approaching municipalities that use their competitor underwriters to generate new business. In this section, we explore the nature of municipality-underwriter relationships.

We find empirically, however, that most municipal issuers are slow to switch lead underwriters, and these persistent, sticky relationships can help explain part of the variation in calling delays. Of course issuers may prefer the underwriter for reasons other than refinancing efficiency (e.g., some other bundled good or service - either observable or unobservable - that the underwriter provides). In addition, small or infrequent issuers may not be able to offer enough business to attract more active underwriters.

Table 9 provides summary statistics on the persistence of the issuer-underwriter relationship. In particular, each municipal issues, on average, $87 \%$ of all of its bonds using the same lead underwriter. Since some issuers may only issue a limited number bonds at once, or issue multiple bonds, as part of the same series, we additionally consider samples of issuers that have issued: at least 20 (Row 2), 40 (Row 3), or 60 bonds (Row 4). We see that a pattern of persistent relationships holds even through these more frequent issuers. Finally, we show that issuers who use Bear Stearns (Row 5) and Lehman (Row 6) have very persistent relationships with these underwriters pre-bankruptcy - a fact we will later use to examine shocks to the underwriter-issuer relationship in Section IV.4.3.

Next, we create a measure that captures the persistence of the issuer-underwriter relationship and explore whether this measure is associated with variation in redemption delays. For each issuer and underwriter pair, our measure is calculated as the dollarweighted percentage of all bonds that are underwritten by the same lead underwriter. To ensure that this relationship is relevant at the time of the refinancing decision (i.e., that there is no look-ahead bias), we examine data solely looking backward at each point in time from the last ten years prior to the bond's call unlock date. For example, suppose a bond's call option unlocked in 2001, and the given municipality underwrote 10 billion dollars of bonds with Lehman from 1991 to 2000. If the bond's issuer issued 40 billion dollars of bonds total over 1991 to 2000, then we would measure its persistence with Lehman as 10/40 or 0.25 in the year 2000. If the bond's issuer did not have any bonds at all underwritten within the last five years, then it is dropped from our sample.

The results exploring underwriter persistence are in Table 10. From Table 10, we find that bonds that use a persistent underwriter are significantly more likely to delay calling, holding as else equal. For instance, Columns 1 and 2 of Table 10 show that Calling All Issuers - 24 
controlling for the bond characteristics and fixed effects shown to impact calling behavior in prior tables, that bonds issued by more persistent underwriter-issuer relationships are associated with significantly longer delays in optimal calling.

In Column 3 of Table 10, we then explore to what extent local resource concentration - positively associated with monitoring in Table 9 - interacts with sticky relationships. In other words, if the long-standing, sticky relationship was with a locally focused underwriter, would that attenuate this negative association of monitoring? From Column 3 of Table 10, this is precisely what appears to happen. As in Table 9, using a locally focused underwriter (main effect on Local Focus) reduces the incidence of call delays on a municipal's bonds. Moreover, since the coefficient on the interaction term is negative and significant, this implies that the sticky relationship that results in significantly more delays is significantly attenuated if that persistent relationship is with an underwriter who has focused resources in - and is attentive to - the local state market.

\section{IV.4.3 Severing a Bond Underwriter's Monitoring Tie: Lehman Brothers' and Bear} Stearns' Bankruptcies

Finally, we use the fall of Lehman Brothers and Bear Stearns during the financial crisis as a quasi-diff-in-diff experiment to explore what happens when a given bond issueunderwriter relationship is disrupted - in this case severed abruptly. This is provided in Table 11. In Columns 1 and 2 of Table 11, we regress a dummy for calling delay greater than one year on a dummy for use of Lehman Brothers or Bear Stearns as lead underwriter for the bond issue, a dummy for years after the fall of Lehman Brothers and Bear Stearns, and an interaction term between the two dummies.

Overall, we find that both the likelihood of redemption delays are on average lower for those bonds who used Lehman Brothers or Bear Stearns as an underwriter, and for those bonds whose redemption options were unlocked post financial crisis than the period prior. However, looking at the coefficient on the interaction term, we find that bond issues using Lehman Brothers or Bear Stearns as lead underwriters are 3.7 percentage points $(\mathrm{t}=2.48)$ more likely to experience longer calling delays than the average bond after their lead underwriters went bankrupt, exiting the market. While there are certainly a number 
of plausible explanations for these dynamics ${ }^{27}$, they are at least consistent with imperfect external monitoring of callable issues by non-lead underwriters (once the underwriters are no longer present) on the given bond issue.

In Column 3 of Table 11, we then conduct a "falsification" test of this being driven solely by large, national banks being distracted during this turmoil period of the financial crisis due to other shocks occurring in their organizations, and thus shirking on monitoring within municipal bonds. Specifically, we consider the comparison set of bonds that used Goldman Sachs as the lead underwriter. We include an indicator for use of Goldman Sachs, and an equivalent interaction term between the Goldman Sachs dummy and the post-crisis indicator. If bonds that used large national underwriting firms simply fared worse due to the financial crisis and were thus less likely to call, then we would expect to find the coefficient on the interaction term of Goldman Sachs to be positive and significant, much like Bear Stearns and Lehman Brothers. However, we find an insignificant (and even negative in point-estimate) coefficient. This falsification test suggests that it was the sudden severing of the tie to the individual underwriters that ultimately led to delayed calling, and not a collective effect from large underwriters over this time period.

\section{Conclusion}

Despite the considerable amount of funding at stake and the real impact of public debt management on the financial wellbeing of towns, cities, states and their taxpayers, relatively little is known regarding refunding decisions of municipalities and their relative efficiency (or inefficiency). In this paper, we document novel evidence of systematic mistakes in this behavior, along with the large value lost through municipals' sub-optimal exercise of their bonds' call options - a point made more central considering the fact that nearly $95 \%$ of long-term bond issues contain call options.

\footnotetext{
${ }^{27}$ Another possible explanation is that due to search frictions, it is costly to find another underwriter. This mechanism is unlikely to drive our findings, because between 2001 and $2007,67 \%$ of bond issues in our sample were sold by a municipal that hired multiple underwriters in the past, and thus, would not have a hard time finding at least one other underwriter.
} 
We calculate that roughly $\$ 1.38$ billion dollars per year are lost by public issuers by delaying the exercise of their early redemptions, totaling over $\$ 26$ billion dollars lost between 2001 and 2018 even after accounting for the costs of issuance and other transaction costs. The sources of this value lost exhibit rich variation across and within many dimensions of the bonds and municipality issuers themselves. They vary over time, across geographies, across issuer size, across bond size, across bond funding structure, and the types of projects funded.

Moreover, we find that there are bond-, issuer-, and underwriter-related factors potentially related to the mechanisms that drive these delays - that are systematically associated with this calling delay behavior. For example, we find that these delays associate with an issuer-workload channel. Bonds whose call options are unlocked at the busy fiscal year-end, or whose call options occur when municipalities are inundated with an abnormal number of other calls are significantly more likely to delay. Moreover, these dynamics are especially true for smaller and less experienced municipalities.

Stepping back, the optimal financial management of public debt is a first order question in finance. We contribute to this evolving field in identifying a novel and economically meaningful channel of current inefficiency in this sizable financial landscape.

We additionally find that there is imperfect alleviation of these inefficiencies through debt-monitoring, and that the industrial organization of this market could play a role in this. A further examination of this market structure could provide potential paths to remedying these monitoring gaps, giving insight more broadly into breakdowns in monitoring chains across a wide range of financial markets along with their potential solutions. 


\section{References}

Agarwal, S., Amromin, G., Ben-David, I., Chomsisengphet, S., Piskorski T., and Seru, A. (2017). Policy intervention in debt renegotiation: evidence from the home affordable modification program, Journal of Political Economy, 125(3): 654-712.

Altinkilic, O., and Hansen, R. S. (2000). Are there economies of scale in underwriting fees? Evidence of rising external financing costs. The Review of Financial Studies, 13(1): 191-218.

Ang, A., Green, R. C., Longstaff, F. A., and Xing, Y. (2017). Advance refundings of municipal bonds. The Journal of Finance, 72(4):1645-1682.

Becker, B., Campello, M., Thell, V., and Yan, D. (2018). Debt overhang and the life cycle of callable bonds. Swedish House of Finance Research Paper, (18-16).

Bliss, R. R., \& Ronn, E. I. (1998). Callable US Treasury bonds: Optimal calls, anomalies, and implied volatilities. The Journal of Business, 71(2), 211-252.

Burch, T. R., Nanda, V., and Warther V. (2005). Does it pay to be loyal? An empirical analysis of underwriting relationships and fees, Journal of Financial Economics, 77(3): 673-699.

Butler, A. W., Fauver, L., and Mortal, S. (2009). Corruption, political connections, and municipal finance. The Review of Financial Studies, 22(7):2873-2905.

Cestau, Dario. "Specialization investments and market power in the underwriting market for municipal bonds." (2020).

Cornaggia, Kimberly Rodgers, John Hund, and Giang Nguyen. The price of safety: The evolution of municipal bond insurance value. Working Paper, available at SSRN 3266890 (2020).

Dagostino, Ramona. The impact of bank financing on municipalities' bond issuance and the real economy. Working Paper, University of Rochester, Rochester, NY (2018).

Dammon, R. M., and Spatt, C. S. (1993). A note on advance refunding of municipal debt, Working paper, Carnegie Mellon University.

Defusco, A. A., and Mondragon, J. (2020). No job, no money, no refi: frictions to refinancing in a recession, The Journal of Finance, 75(5): 2327-2376.

Drucker, S., and Puri, M. (2005). On the benefits of concurrent lending and underwriting, The Journal of Finance, 60(6): 2762-2799.

Dyl, E. A. and Joehnk, M. D. (1976). Refunding tax exempt bonds. Financial Management, pages 59-66.

Fernando, C. S., May, A. D., and Megginson, W. L. (2012). The value of investment banking relationships: evidence from the collapse of Lehman Brothers. The Journal of Finance, 67(1): 235-270.

Fischer, E. O., Heinkel, R., Zechner, J., 1989. Dynamic recapitalization policies and the role of call premia and issue discounts. Journal of Financial and Quantitative Analysis, 427-446.

Gao, P., Lee, C., and Murphy, D. (2019a). Municipal borrowing costs and state policies for distressed municipalities. Journal of Financial Economics, 132(2):404-426.

Gao, P., Murphy, D., and Qi, Y. (2019b). Political uncertainty and public financing costs: Evidence from US gubernatorial elections and municipal bond markets. Available at SSRN 1992200.

Garrett, Daniel. Conflicts of interest in municipal bond advising and underwriting. Available at SSRN 3835504 (2021). 
Hansen, R. S., and Torregrosa, P. (1992). Underwriter compensation and corporate monitoring. The Journal of Finance, 47(4): 1537-1555.

Ingersoll, J. (1977). An examination of corporate call policies on convertible securities. The Journal of Finance, 32(2), 463-478.

Jacoby, G., \& Shiller, I. (2010). Corporate bond pricing and the effects of endogenous default and call options. The Journal of Fixed Income, 20(2), 80-100.

Jarrow, R., Li, H., Liu, S., \& Wu, C. (2010). Reduced-form valuation of callable corporate bonds: Theory and evidence. Journal of Financial Economics, 95(2), 227-248.

Joffe, Marc D. "Municipal bond costs of issuance." Available at SSRN 2650226 (2015).

Jordan, B. D., Jordan, S. D., \& Jorgensen, R. D. (1995). A reexamination of option values implicit in callable Treasury bonds. Journal of Financial Economics, 38(2), 141-162.

Kalotay, A. J., and May, W. H. (1998). The timing of advance refunding of tax-exempt municipal bonds, Municipal Finance Journal Fall, 1-15.

Kalotay, A. J., and Abreo, L. (2010). Making the right call, Credit, October, 57-59.

King, T. H. D. (2002). An empirical examination of call option values implicit in US corporate bonds. Journal of Financial and Quantitative Analysis, 693-721.

King, T. H. D., and Mauer, D. C. (2000). Corporate Call Policy for Nonconvertible Bonds. Journal of Business, 73(3): 403-444.

Kraus, A., 1983. An analysis of call provisions and the corporate refunding decision. Midland Corporate Finance Journal, 1-17.

Longstaff, Francis A. (1992). Are negative option prices possible? The callable US Treasury-Bond puzzle. Journal of Business: 571-592.

Longstaff, F. A. and Schwartz, E. S. (2001). Valuing American options by simulation: a simple least-squares approach. The Review of Financial Studies, 14(1):113-147.

Longstaff, F. A., Tuckman, B. A., 1994. Calling nonconvertible debt and the problem of related wealth transfer effects. Financial Management, 21-27.

Ljungqvist, A., and Wilhelm, W. J. Jr. (2003). IPO pricing in the dot-com bubble, The Journal of Finance, 58(2): 723-752.

Mauer, D. C., 1993. Optimal bond call policies under transactions costs. Journal of Financial Research, 23-37.

Moldogaziev, T. T. and Luby, M. J. (2012). State and local government bond refinancing and the factors associated with the refunding decision. Public Finance Review, 40(5):614-642.

Nakhmurina, Anya. Does fiscal monitoring make better governments? Evidence from US municipalities. (2020). Working Paper.

Pye, G. (1975). The value of the call option on a bond. In Stochastic Optimization Models in Finance, pages 547-552. Elsevier.

Ritter, J. R., and Welch, I. (2002). A review of IPO activity, pricing, and allocations. The Journal of Finance, 57(4): 1795-1828.

Vijayakumar, J. (1995). An empirical analysis of the factors influencing call decisions of local government bonds. Journal of Accounting and Public Policy, 14(3):203-231.

$\mathrm{Vu}$, J. D. (1986). An empirical investigation of calls of non-convertible bonds. Journal of Financial Economics, 16(2), 235-265.

$\mathrm{Xu}$, Q. (2018). Kicking maturity down the road: early refinancing and maturity management in the corporate bond market. The Review of Financial Studies, 31(8), 3061-3097.

Yasuda, A. (2005). Do bank relationships affect the firm's underwriter choice in the corporate-bond underwriting market? The Journal of Finance, 60(3): 1259-1292. 
Figure 1. Par Value of Immediately Callable Bonds

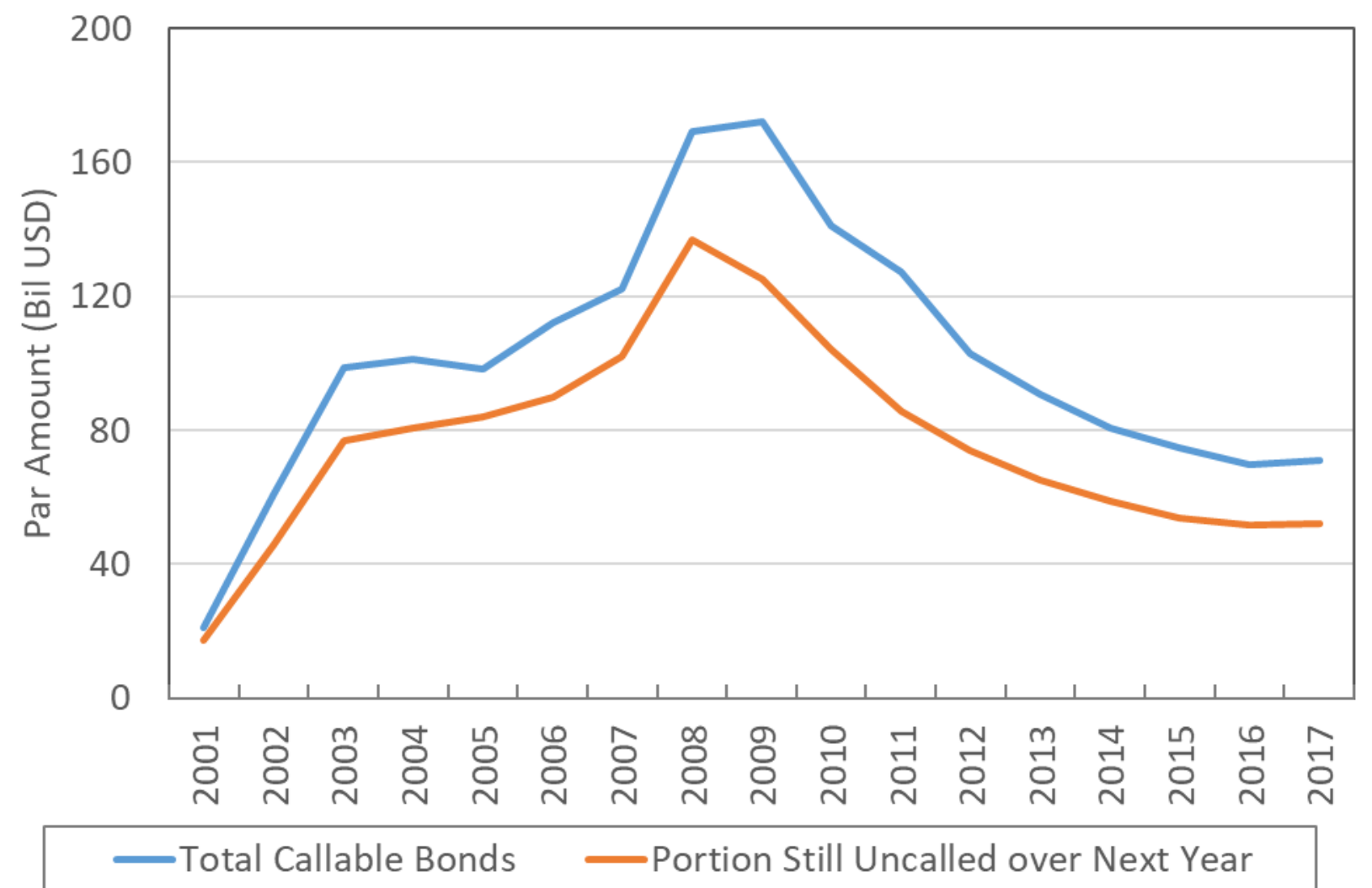

Notes: The blue line is the total par value of municipal bonds (in billions USD) outstanding that could be immediately called at the beginning of each year. The orange line represents the portion of these bonds that still haven't been redeemed by the end of that calendar year. The underlying municipal data comes from the Mergent Bond database. 
Figure 2. The Estimated Value Lost of Municipal versus Corporate Bonds

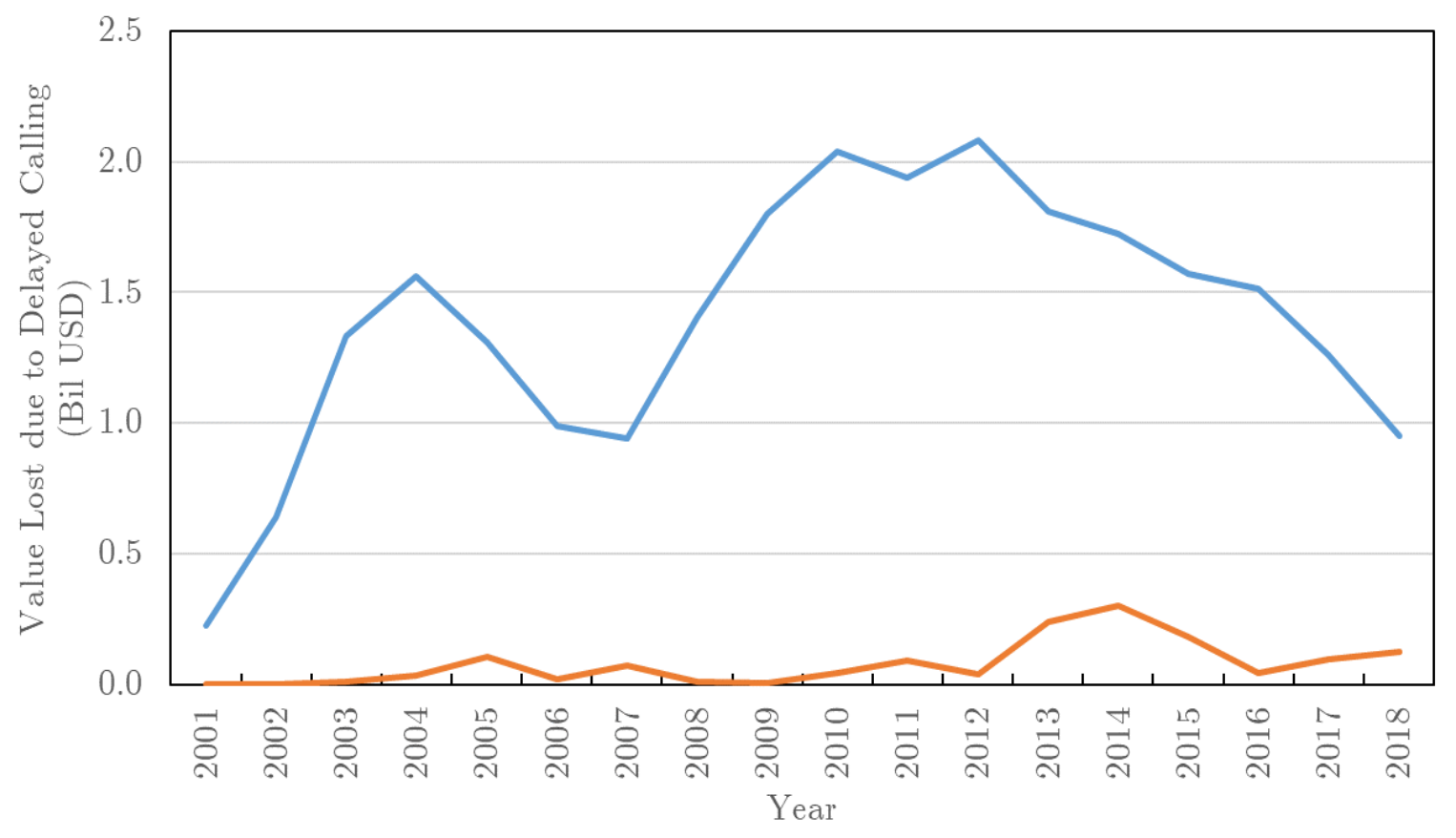

—Municipal Bonds —Corporate Bonds

Notes: The figure above plots the estimated annual value lost by municipal (blue line) and corporate (orange line) issuers due to delays in the utilization of their redemption options. For exact calculations, see Section IV.2. The underlying municipal data comes from the Mergent Bond database, and the underlying corporate bond data comes from the Mergent FISD database. 


\section{Figure 3. Characteristics of Callable Bonds}

Panel A. Coupon Rates

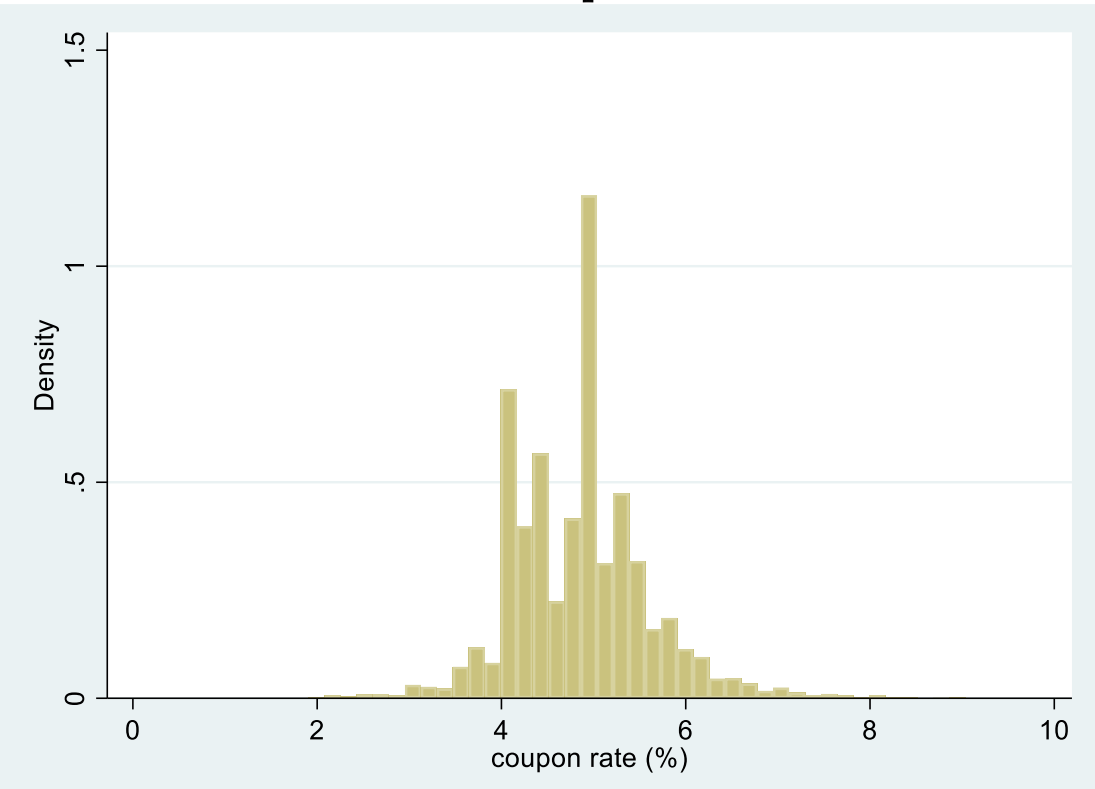

Panel B. Years Left to Maturity

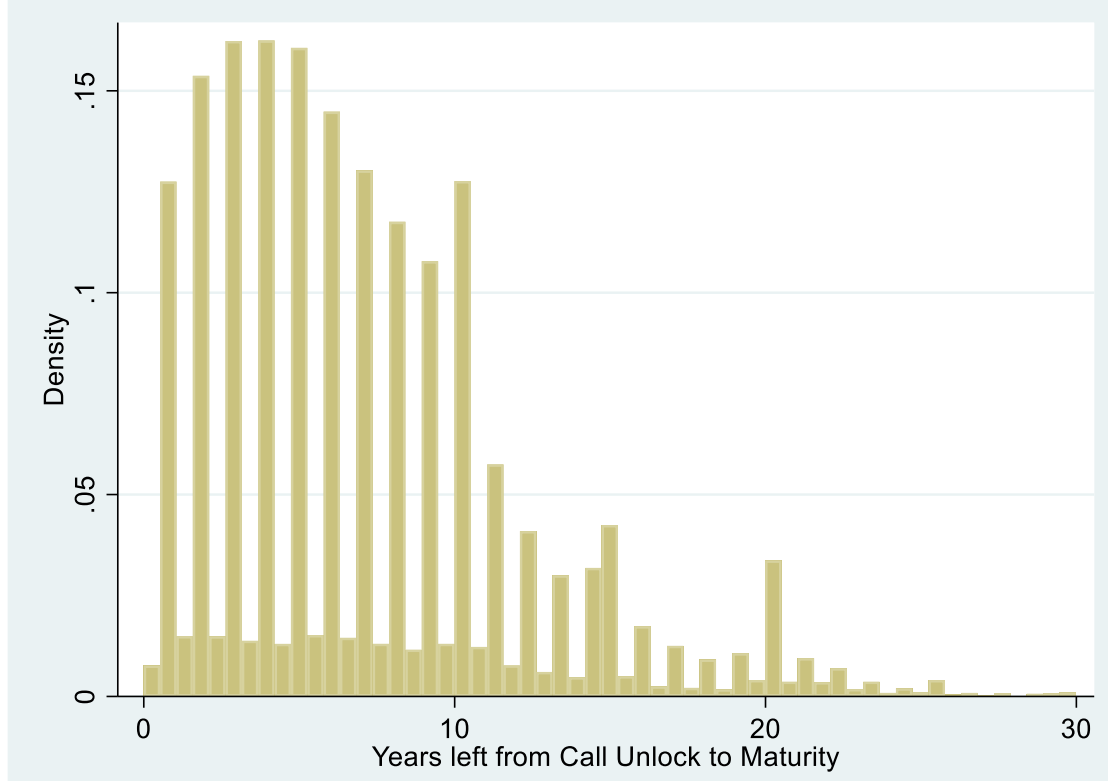

Notes: Panel A shows the histogram of coupon rates and Panel B describes the number of years left until maturity after the call unlock date (Panel B) for bonds whose call options were unlocked between January $1^{\text {st }} 2001$ and December 31, 2018. The data comes from the Mergent Bond Database. 
Figure 4. Offering Yields by Rating

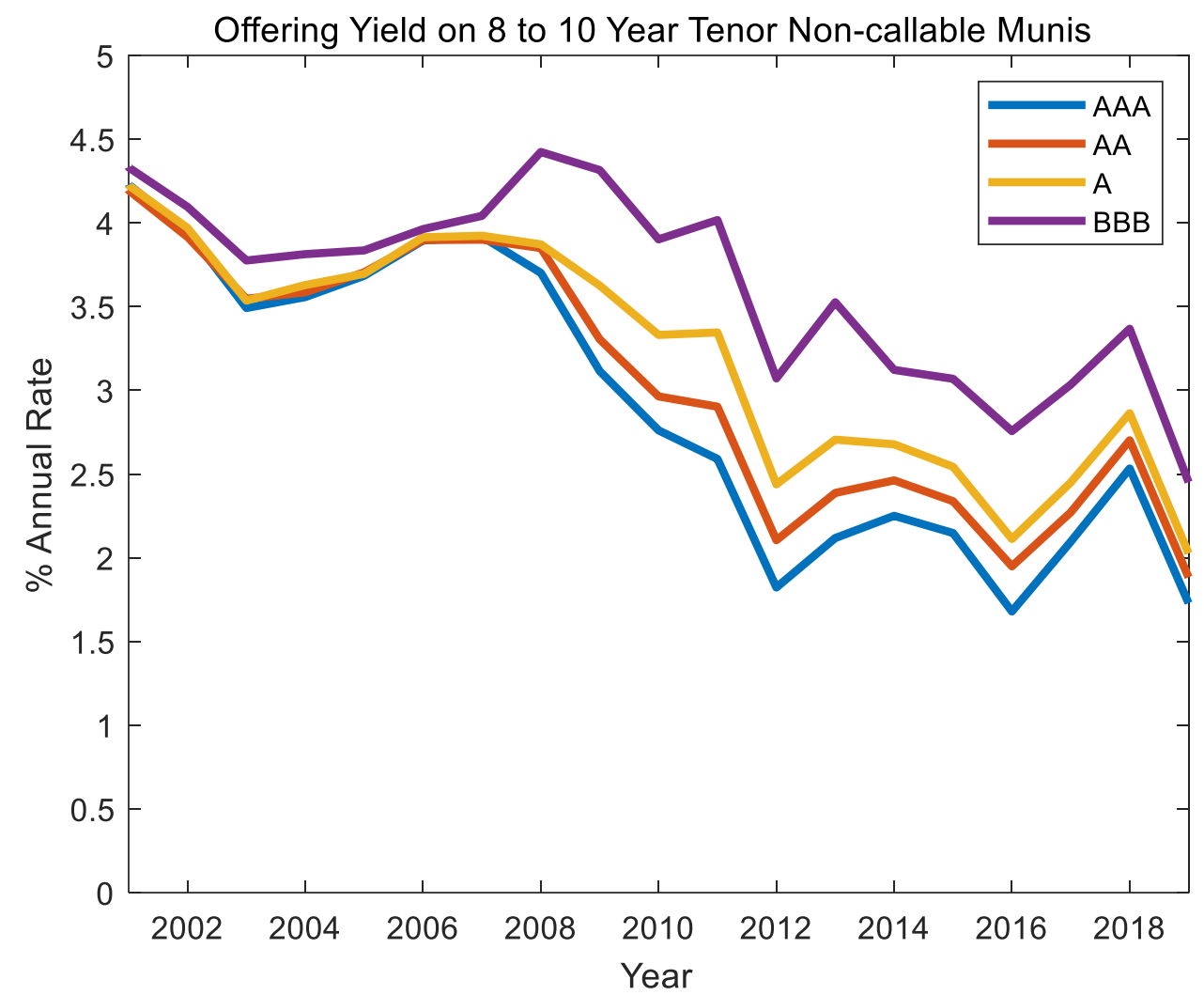

Notes: The figure above shows the time series average offering yield on all municipal bonds with eight to ten-year maturity and without a callable option issued each year between 2001 and 2019. Each line refers to a different rating category as reported by Standard and Poor. 
Figure 5. Redemption Variation by State

Panel A. Pct of Bonds that Call with more than One-year Delay

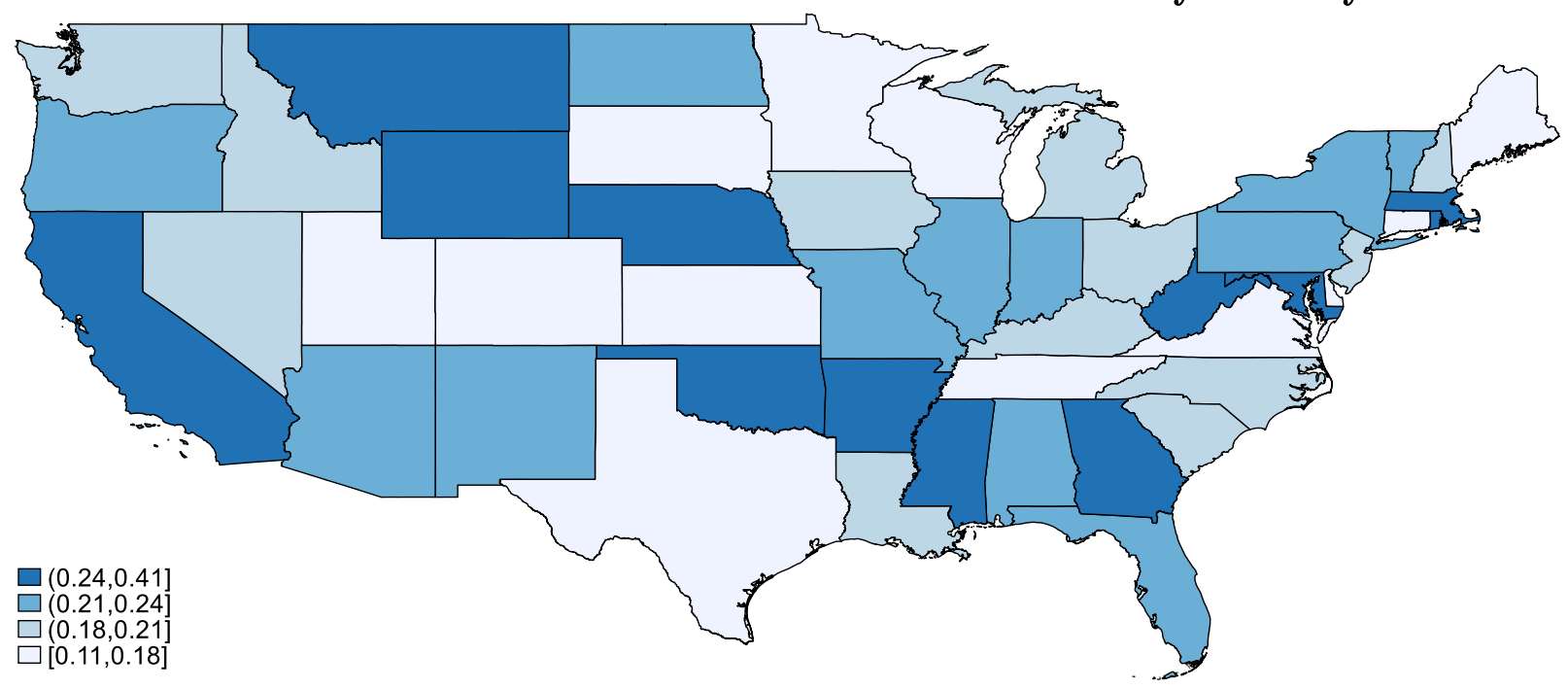

Panel B. Pct of Bonds that Never Call

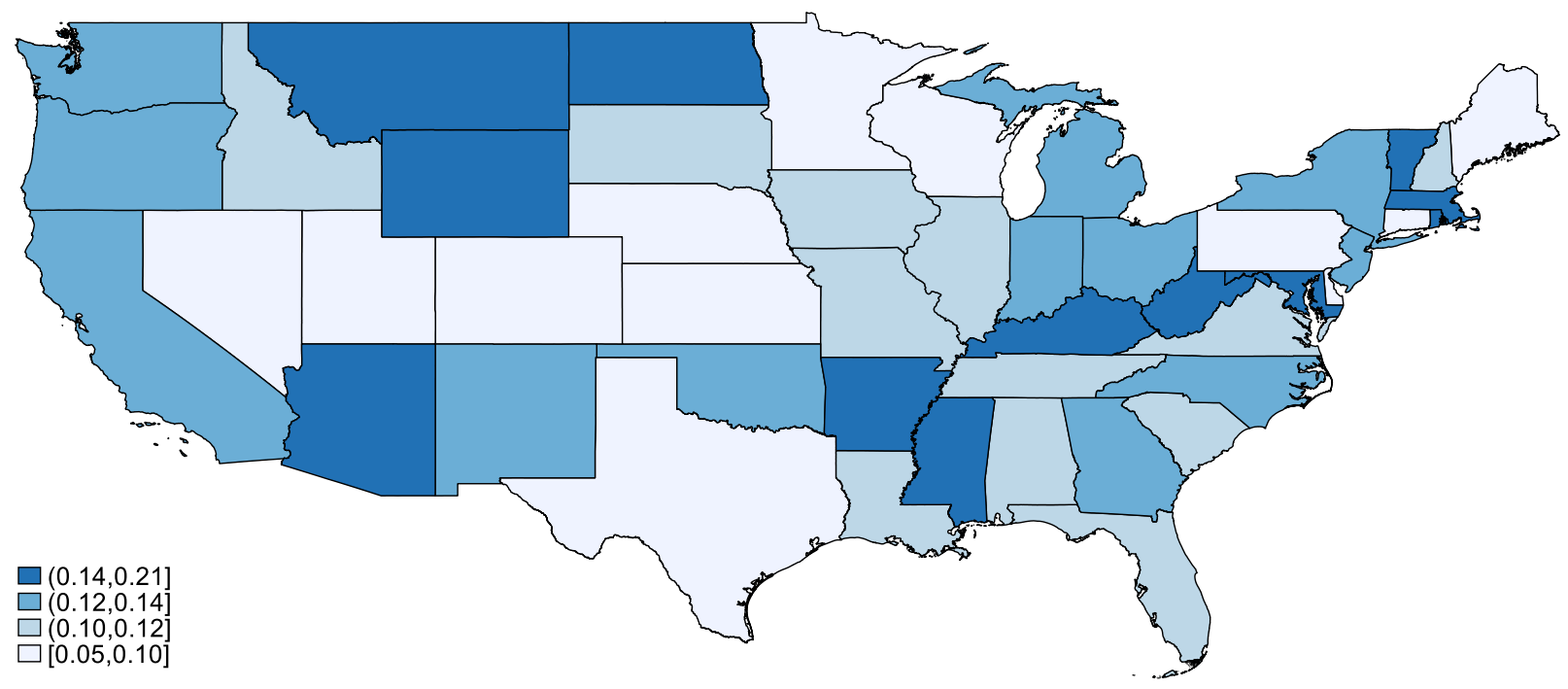

Notes: The figure above shows the percent of bonds by state that call with at least one year delay (Panel A) as well as the percent of bonds that never call (Panel B). The lightest colors correspond to states that are least likely to delay (not call) and the darkest colors correspond to states that are most likely to delay (not call) in Panel A (Panel B). The data comes from the Mergent Bond Database and covers all bonds with a call option that unlocked between January 1, 2001 and December 31, 2018. 


\section{Figure 6. Geographic Focus of Large Underwriters}

Panel A. Citigroup

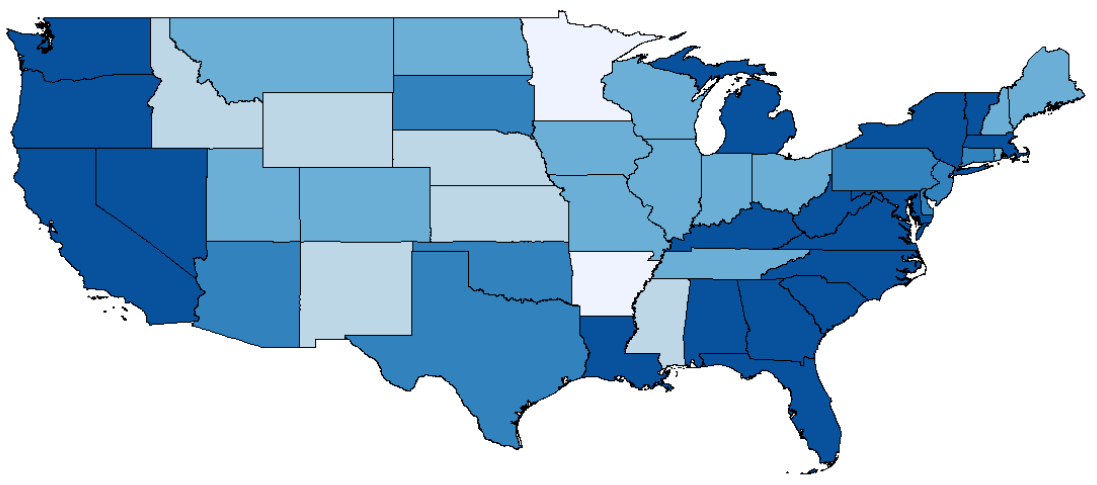

Panel B. Morgan Keegan

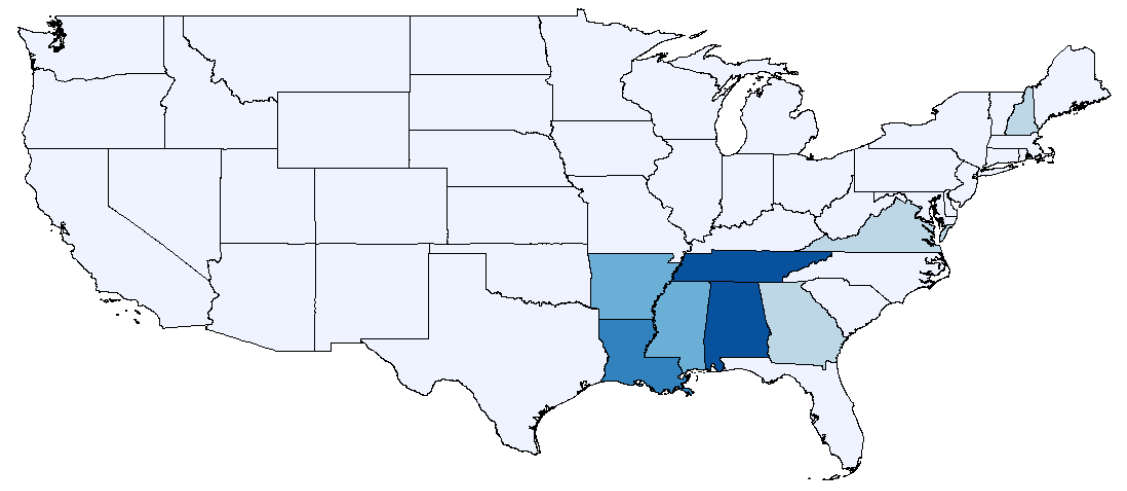

Panel C. Dougherty

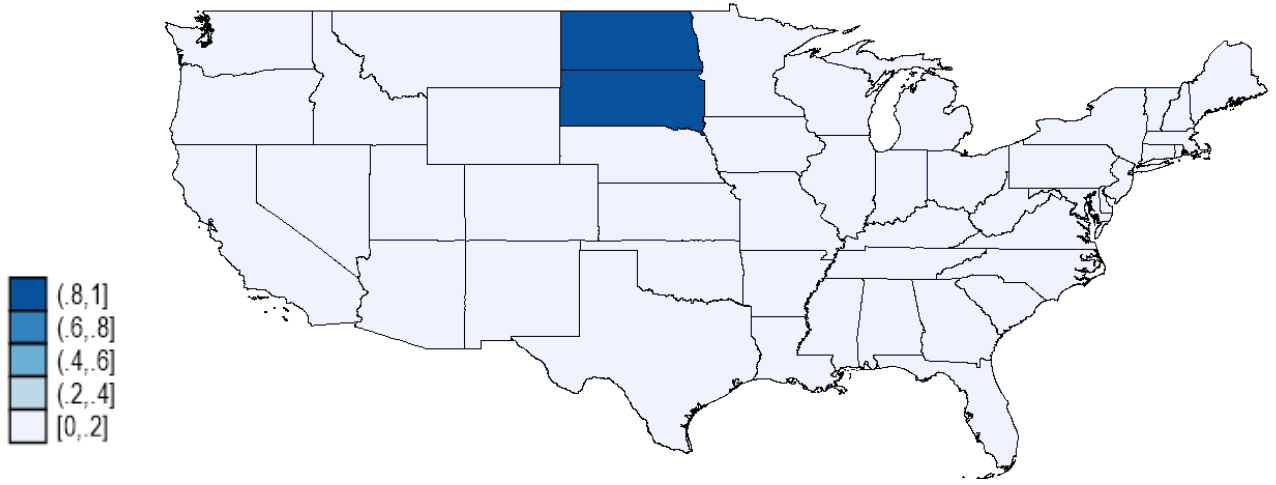

Notes: The figure above shows the local focus of three large municipal underwriters in our sample: Citigroup (Panel A), Morgan Keegan (Panel B), and Dougherty (Panel C). Locally Focused is calculated as the total amount underwritten in each state divided by the total amount underwritten by the largest underwriter in the state between years 2001 and 2018. This variable ranges between 0 (the firm does not underwrite at all in given state) to 1 (the firm is the top underwriter in given state). The data comes from the Mergent Bond Database. 
Table 1. Summary Statistics of Municipal Bonds

\begin{tabular}{|c|c|c|c|c|c|}
\hline Variable & $\begin{array}{l}\text { Num } \\
\text { Obs }\end{array}$ & Mean & $\begin{array}{l}\text { Std } \\
\text { Dev }\end{array}$ & Min & Max \\
\hline Offering Yield (\%) & 211,942 & 4.96 & 0.93 & 2.00 & 10.00 \\
\hline Offering Price (USD) & 211,942 & 99.82 & 3.51 & 94.56 & 111.54 \\
\hline Coupon Rate (\%) & 211,942 & 4.95 & 0.91 & 0.00 & 11.25 \\
\hline Maturity (years) & 211,942 & 16.52 & 5.49 & 10.50 & 49.78 \\
\hline Mos from Call Unlock to Maturity & 211,942 & 93.31 & 71.72 & 1.00 & 508.47 \\
\hline Offering Year & 211,942 & 2000.75 & 5.54 & 1974 & 2019 \\
\hline Dummy for Delayed & 211,942 & 0.59 & 0.49 & 0.00 & 1.00 \\
\hline Dummy for Credit Downgrade & 211,942 & 0.04 & 0.19 & 0.00 & 1.00 \\
\hline Total Offering Amount (mil USD) & 211,942 & 3.21 & 11.90 & 0.15 & $1,830.00$ \\
\hline
\end{tabular}

Notes: The table above shows summaries of key bond variables the baseline sample that is used in our main regressions. This sample includes all callable bonds with greater than ten years in maturity that have not already been advance refunded as of the date on which their call option unlocks. The data comes from the Mergent Bond Database and covers all bonds with a call option that unlocked between January 1, 2001 and December 31, 2018. 
Table 2. Summary of Calling by State

\begin{tabular}{|c|c|c|c|c|c|c|}
\hline State & $\begin{array}{l}\text { Total Size } \\
\text { (bil USD) } \\
\end{array}$ & $\begin{array}{c}\text { p25 Years } \\
\text { Delayed }\end{array}$ & $\begin{array}{c}\text { p50 Years } \\
\text { Delayed }\end{array}$ & $\begin{array}{c}\text { p75 Years } \\
\text { Delayed }\end{array}$ & $\begin{array}{c}\text { \% Delay } \\
\text { Year }+ \\
\end{array}$ & $\begin{array}{c}\text { \% Never } \\
\text { Call } \\
\end{array}$ \\
\hline CA & 344.62 & 0.11 & 1.45 & 5.71 & 35.37 & 13.57 \\
\hline NY & 324.76 & 0.00 & 0.50 & 4.65 & 23.23 & 13.06 \\
\hline TX & 232.02 & 0.00 & 0.42 & 2.17 & 16.07 & 8.19 \\
\hline FL & 135.25 & 0.00 & 0.35 & 2.58 & 23.45 & 10.77 \\
\hline PA & 111.66 & 0.00 & 0.23 & 1.76 & 20.99 & 10.13 \\
\hline IL & 99.02 & 0.00 & 0.42 & 3.13 & 21.21 & 11.90 \\
\hline NJ & 81.48 & 0.00 & 0.50 & 30.42 & 20.13 & 13.40 \\
\hline MA & 81.11 & 0.00 & 0.50 & 4.75 & 27.19 & 17.79 \\
\hline WA & 67.96 & 0.00 & 0.44 & 15.25 & 19.60 & 12.57 \\
\hline $\mathrm{OH}$ & 67.93 & 0.00 & 0.36 & 3.97 & 19.37 & 12.94 \\
\hline MI & 59.66 & 0.00 & 0.44 & 5.50 & 20.74 & 13.13 \\
\hline VA & 51.12 & 0.00 & 0.28 & 3.75 & 17.83 & 11.11 \\
\hline OR & 49.58 & 0.00 & 0.53 & 6.00 & 23.59 & 13.46 \\
\hline $\mathrm{CO}$ & 45.59 & 0.00 & 0.14 & 2.97 & 16.89 & 10.37 \\
\hline $\mathrm{AZ}$ & 43.74 & 0.00 & 0.43 & 30.42 & 23.62 & 15.33 \\
\hline $\mathrm{MN}$ & 41.14 & 0.00 & 0.31 & 2.00 & 16.84 & 8.04 \\
\hline IN & 40.53 & 0.00 & 0.42 & 5.39 & 21.39 & 13.25 \\
\hline GA & 39.82 & 0.00 & 0.45 & 2.80 & 27.14 & 13.41 \\
\hline $\mathrm{NC}$ & 38.72 & 0.00 & 0.35 & 30.42 & 20.38 & 13.96 \\
\hline MO & 37.20 & 0.00 & 0.45 & 3.44 & 21.32 & 11.84 \\
\hline $\mathrm{CT}$ & 35.40 & 0.00 & 0.08 & 1.37 & 12.22 & 5.75 \\
\hline MD & 35.34 & 0.00 & 0.45 & 30.42 & 24.35 & 16.01 \\
\hline LA & 31.64 & 0.00 & 0.33 & 4.47 & 20.12 & 12.51 \\
\hline $\mathrm{SC}$ & 31.63 & 0.00 & 0.43 & 3.99 & 21.87 & 12.19 \\
\hline WI & 31.15 & 0.00 & 0.01 & 1.47 & 14.02 & 8.26 \\
\hline $\mathrm{TN}$ & 28.20 & 0.00 & 0.21 & 2.50 & 18.96 & 11.77 \\
\hline NV & 25.71 & 0.00 & 0.08 & 3.00 & 18.83 & 9.29 \\
\hline $\mathrm{KY}$ & 24.65 & 0.00 & 0.50 & 27.92 & 20.98 & 14.07 \\
\hline $\mathrm{AL}$ & 19.03 & 0.00 & 0.44 & 2.12 & 23.10 & 10.58 \\
\hline $\mathrm{KS}$ & 17.40 & 0.00 & 0.21 & 1.97 & 16.74 & 7.85 \\
\hline $\mathrm{NE}$ & 15.96 & 0.04 & 0.56 & 2.09 & 30.88 & 9.73 \\
\hline $\mathrm{AR}$ & 15.26 & 0.17 & 0.88 & 2.28 & 37.53 & 17.49 \\
\hline UT & 15.00 & 0.00 & 0.00 & 0.91 & 12.43 & 8.66 \\
\hline HI & 14.01 & 0.00 & 0.35 & 5.96 & 12.16 & 8.14 \\
\hline OK & 13.62 & 0.00 & 0.44 & 2.30 & 22.72 & 12.12 \\
\hline IA & 11.54 & 0.00 & 0.22 & 1.97 & 19.65 & 12.13 \\
\hline AK & 10.94 & 0.00 & 0.31 & 1.49 & 16.19 & 6.13 \\
\hline NM & 10.85 & 0.00 & 0.50 & 4.62 & 23.29 & 14.31 \\
\hline $\mathrm{RI}$ & 10.30 & 0.07 & 1.00 & 30.42 & 30.09 & 16.50 \\
\hline MS & 9.66 & 0.00 & 1.12 & 30.50 & 30.83 & 18.94 \\
\hline $\mathrm{NH}$ & 8.29 & 0.00 & 0.30 & 2.50 & 18.53 & 11.94 \\
\hline WV & 8.19 & 0.22 & 2.14 & 30.42 & 40.70 & 20.93 \\
\hline $\mathrm{ME}$ & 7.48 & 0.00 & 0.30 & 1.91 & 17.42 & 10.24 \\
\hline $\mathrm{DE}$ & 6.00 & 0.00 & 0.32 & 1.25 & 12.57 & 5.87 \\
\hline ID & 5.94 & 0.00 & 0.50 & 9.98 & 19.34 & 11.76 \\
\hline MT & 4.93 & 0.02 & 1.00 & 5.78 & 28.27 & 15.41 \\
\hline SD & 4.53 & 0.00 & 0.21 & 2.00 & 17.99 & 11.32 \\
\hline ND & 3.97 & 0.00 & 0.68 & 2.97 & 23.20 & 13.94 \\
\hline $\mathrm{VT}$ & 3.37 & 0.10 & 1.64 & 60.92 & 25.72 & 17.80 \\
\hline WY & 2.97 & 0.00 & 0.50 & 3.00 & 23.85 & 15.42 \\
\hline
\end{tabular}

Notes: The table above summarizes calling behavior by state. Columns 3-5 reports the $25^{\text {th }}, 50^{\text {th }}$, and $75^{\text {th }}$ percentile for the number of years between when a bond's call option is unlocked and when the bond is called, Column 6 shows the percent of all bonds which waited at least one year to call, and Column 7 shows the percent of all bonds which never called. The data comes from the Mergent Bond Database and covers all bonds with a call option that unlocked between January 1, 2001 and December 31, 2018. 
Table 3. Summary of Calling by Bond Type

\begin{tabular}{|c|c|c|c|c|c|c|}
\hline Type & $\begin{array}{l}\text { Total Size } \\
\text { (bil USD) }\end{array}$ & $\begin{array}{l}\text { p25 Years } \\
\text { Delayed }\end{array}$ & $\begin{array}{l}\text { p50 Years } \\
\text { Delayed }\end{array}$ & $\begin{array}{l}\text { p75 Years } \\
\text { Delayed }\end{array}$ & $\begin{array}{l}\% \text { Delay } \\
\text { Year+ }\end{array}$ & $\begin{array}{l}\% \text { Never } \\
\text { Call }\end{array}$ \\
\hline Revenue & 890.01 & 0.00 & 0.48 & 2.97 & 23.71 & 11.88 \\
\hline G.O. & 704.98 & 0.00 & 0.44 & 3.01 & 17.79 & 10.56 \\
\hline Loan Agreement & 291.70 & 0.00 & 0.80 & 4.43 & 32.73 & 14.21 \\
\hline Mortgage Loans & 147.03 & 0.18 & 1.26 & 7.09 & 25.92 & 12.54 \\
\hline Lease/Rent & 125.95 & 0.00 & 0.64 & 7.10 & 24.73 & 14.53 \\
\hline Limited G.O. & 64.15 & 0.00 & 0.45 & 2.33 & 22.78 & 14.33 \\
\hline Sales/Excise Tax & 55.24 & 0.00 & 0.27 & 2.37 & 19.25 & 10.58 \\
\hline US Government & 37.36 & 0.00 & 0.00 & 0.00 & 7.23 & 3.71 \\
\hline Tobacco Agreement & 33.61 & 0.00 & 0.86 & 4.00 & 30.39 & 15.84 \\
\hline Special Tax & 33.36 & 0.80 & 2.91 & 8.50 & 52.75 & 15.95 \\
\hline Tax Allocation & 20.51 & 0.42 & 2.00 & 8.17 & 51.53 & 22.32 \\
\hline Double barreled & 20.13 & 0.00 & 0.55 & 3.63 & 24.42 & 14.24 \\
\hline Special Assessment & 13.44 & 0.22 & 2.00 & 7.50 & 37.31 & 17.90 \\
\hline Fuel / Vehicle Tax & 11.89 & 0.00 & 0.28 & 2.81 & 15.91 & 8.41 \\
\hline Loan Agreement & 9.43 & 0.04 & 1.18 & 5.37 & 38.68 & 14.67 \\
\hline Tuition Agreement & 5.93 & 0.00 & 0.17 & 1.65 & 20.61 & 9.80 \\
\hline Education Loans & 4.42 & 0.00 & 1.48 & 30.42 & 32.96 & 19.38 \\
\hline Other & 1.52 & 0.00 & 0.80 & 2.02 & 32.70 & 17.30 \\
\hline Public Improvement & 0.44 & 0.00 & 1.02 & 30.42 & 31.20 & 14.40 \\
\hline
\end{tabular}

Notes: The table above summarizes bond characteristics and calling behavior by bond type. Columns 3-5 reports the $25 \mathrm{th}, 50 \mathrm{th}$, and 75 th percentiles for the number of years between when a bond's call option is unlocked and when the bond is called, Column 6 shows the percent of all bonds which waited at least one year to call, and Column 7 shows the percent of all bonds which never called. The data comes from the Mergent Bond Database and covers all bonds with a call option that unlocked between January 1, 2001 and December 31, 2018. 
Table 4. Summary by Credit Rating at Time of Call Unlock

\begin{tabular}{|c|c|c|c|c|c|c|}
\hline Rating & $\begin{array}{l}\text { Total Size } \\
\text { (bil USD) }\end{array}$ & $\begin{array}{l}\text { p25 Years } \\
\text { Delayed }\end{array}$ & $\begin{array}{l}\text { p50 Years } \\
\text { Delayed }\end{array}$ & $\begin{array}{l}\text { p75 Years } \\
\text { Delayed }\end{array}$ & $\begin{array}{l}\% \text { Delay } \\
\text { Year+ }\end{array}$ & $\begin{array}{l}\% \text { Never } \\
\text { Call }\end{array}$ \\
\hline $\mathrm{AAA}$ & 454.69 & 0.07 & 1.00 & 4.15 & 25.24 & 9.92 \\
\hline $\mathrm{AA}$ & 797.52 & 0.00 & 0.32 & 1.39 & 13.38 & 6.34 \\
\hline A & 221.00 & 0.00 & 0.61 & 2.15 & 24.34 & 9.06 \\
\hline $\mathrm{BBB}$ & 61.60 & 0.08 & 0.92 & 3.08 & 31.55 & 10.31 \\
\hline $\mathrm{BB}$ & 8.01 & 0.63 & 1.91 & 4.62 & 63.19 & 21.99 \\
\hline B & 10.34 & 1.79 & 3.84 & 7.15 & 75.00 & 22.95 \\
\hline $\mathrm{CCC}$ & 2.09 & 2.08 & 4.17 & 30.42 & 81.82 & 36.36 \\
\hline
\end{tabular}

Notes: The table above summarizes bond characteristics and calling behavior by credit rating at the time the call option unlocked and whether the bond experienced a credit downgrade since issuance. Columns 35 reports the $25 \mathrm{th}, 50 \mathrm{th}$, and 75 th percentiles for the number of years between when a bond's call option is unlocked and when the bond is called, Column 6 shows the percent of all bonds which waited at least one year to call, and Column 7 shows the percent of all bonds which never called. The data comes from the Mergent Bond Database and covers all bonds with a call option that unlocked between January 1, 2001 and December 31, 2018. Ratings data comes from Capital IQ s Standard and Poor ratings database. 
Table 5. Bond Characteristics Explaining Variation in Calling Delays

\begin{tabular}{|c|c|c|c|c|c|c|}
\hline & (1) & $(2)$ & $(3)$ & $(4)$ & (5) & (6) \\
\hline & \multicolumn{6}{|c|}{ Dummy for Delayed } \\
\hline Coupon (\%) & $\begin{array}{c}-0.095^{* * *} \\
(0.006)\end{array}$ & & & & & $\begin{array}{c}-0.052^{* * *} \\
(0.009)\end{array}$ \\
\hline Offering Yield (\%) & & $\begin{array}{c}-0.090^{* * *} \\
(0.006)\end{array}$ & & & & $\begin{array}{c}-0.039^{* * *} \\
(0.010)\end{array}$ \\
\hline $\begin{array}{l}\text { Dummy for } \\
\text { Downgraded }\end{array}$ & & & $\begin{array}{c}0.088^{* * *} \\
(0.019)\end{array}$ & & & $\begin{array}{c}0.090^{* * *} \\
(0.018)\end{array}$ \\
\hline Months to Maturity & & & & $\begin{array}{c}0.003^{* *} \\
(0.001)\end{array}$ & & $\begin{array}{c}0.021^{* * *} \\
(0.001)\end{array}$ \\
\hline Ln Size (USD) & & & & & $\begin{array}{c}-0.048^{* * *} \\
(0.003)\end{array}$ & $\begin{array}{c}-0.048^{* * *} \\
(0.003)\end{array}$ \\
\hline Observations & 211,942 & 211,942 & 211,942 & 211,942 & 211,942 & 211,942 \\
\hline R-squared & 0.178 & 0.175 & 0.162 & 0.161 & 0.176 & 0.193 \\
\hline State FE & YES & YES & YES & YES & YES & YES \\
\hline Year FE & YES & YES & YES & YES & YES & YES \\
\hline Capital Purpose FE & YES & YES & YES & YES & YES & YES \\
\hline Initial Rating FE & YES & YES & YES & YES & YES & YES \\
\hline
\end{tabular}

Notes: The table above shows the coefficients from regressing the decision to delay calling a bond on different bond characteristics. The sample includes all callable bonds that have not been advance refunded on the date that the bond's call option unlocks. The outcome variable, Dummy for Delayed, is equal to one if the bond was called at least one year after its call option unlocked, or it was never called. Explanatory bond characteristics include: the coupon rate, the listed offering yield, a dummy for whether the bond was downgraded since issuance, the number of days remaining from the date the call option unlocked until maturity, and the natural log of the issuance par size. In addition, we add fixed effects for state, year, capital purpose, and the initial credit rating of the issuer. The data comes from the Mergent Bond Database and covers all bonds with a call option that unlocked between January 1, 2001 and December 31, 2018. 
Table 6. Regressions Explaining Delay Time using Fiscal Calendar

\begin{tabular}{|c|c|c|c|c|}
\hline & $(1)$ & $(2)$ & $(3)$ & (4) \\
\hline DEPENDENT VARIABLES: & \multicolumn{4}{|c|}{ Avg Wait Time (Yrs) } \\
\hline Month before FY End & $\begin{array}{l}-0.038 \\
(0.155)\end{array}$ & & $\begin{array}{l}-0.131 \\
(0.167)\end{array}$ & $\begin{array}{l}-0.102 \\
(0.116)\end{array}$ \\
\hline FY End & $\begin{array}{r}0.204^{* * *} \\
(0.047)\end{array}$ & & $\begin{array}{r}0.188^{* * *} \\
(0.072)\end{array}$ & $\begin{array}{l}-0.130 \\
(0.083)\end{array}$ \\
\hline Month after FY End & $\begin{array}{l}0.010 \\
(0.042)\end{array}$ & & $\begin{array}{l}-0.001 \\
(0.052)\end{array}$ & $\begin{array}{c}0.037 \\
(0.047)\end{array}$ \\
\hline Dummy for Small Issuer & & $\begin{array}{r}0.109^{* * *} \\
(0.023)\end{array}$ & $\begin{array}{r}0.103^{* * *} \\
(0.023)\end{array}$ & \\
\hline \multicolumn{5}{|l|}{ Interaction Terms } \\
\hline Small * Month before FY End & & & $\begin{array}{c}0.604^{* *} \\
(0.269)\end{array}$ & \\
\hline Small * FY End & & & $\begin{array}{r}0.068 \\
(0.134)\end{array}$ & \\
\hline $\begin{array}{l}\text { Small * Month after FY } \\
\text { End }\end{array}$ & & & $\begin{array}{c}0.036 \\
(0.071)\end{array}$ & \\
\hline
\end{tabular}

\section{Control Variables}

\begin{tabular}{|c|c|c|c|c|}
\hline Coupon (\%) & $\begin{array}{c}-0.100^{* * *} \\
(0.037)\end{array}$ & $\begin{array}{c}-0.096^{* * *} \\
(0.037)\end{array}$ & $\begin{array}{c}-0.097^{* * *} \\
(0.036)\end{array}$ & $\begin{array}{l}-0.046 \\
(0.040)\end{array}$ \\
\hline Offering Yield (\%) & $\begin{array}{l}0.022 \\
(0.038)\end{array}$ & $\begin{array}{l}0.010 \\
(0.038)\end{array}$ & $\begin{array}{c}0.007 \\
(0.037)\end{array}$ & $\begin{array}{l}0.032 \\
(0.039)\end{array}$ \\
\hline Downgraded & $\begin{array}{c}0.172^{* * *} \\
(0.055)\end{array}$ & $\begin{array}{c}0.172^{* * *} \\
(0.055)\end{array}$ & $\begin{array}{c}0.176^{* * *} \\
(0.055)\end{array}$ & $\begin{array}{r}0.125^{* *} \\
(0.061)\end{array}$ \\
\hline Months to Maturity & $\begin{array}{c}0.005^{* * *} \\
(0.001)\end{array}$ & $\begin{array}{c}0.005^{* * *} \\
(0.001)\end{array}$ & $\begin{array}{c}0.005^{* * *} \\
(0.001)\end{array}$ & $\begin{array}{l}0.007^{* * *} \\
(0.001)\end{array}$ \\
\hline Ln Size (USD) & $\begin{array}{c}-0.039^{* * *} \\
(0.012)\end{array}$ & $\begin{array}{c}-0.031^{* *} \\
(0.013)\end{array}$ & $\begin{array}{r}-0.031^{* *} \\
(0.013)\end{array}$ & $\begin{array}{c}-0.053^{* * *} \\
(0.010)\end{array}$ \\
\hline Sample & $\begin{array}{l}\text { Non-prerefunded } \\
\text { GO Bonds }\end{array}$ & $\begin{array}{l}\text { Non-prerefunded } \\
\text { GO Bonds }\end{array}$ & $\begin{array}{l}\text { Non-prerefunded } \\
\text { GO Bonds }\end{array}$ & $\begin{array}{l}\text { Non-prerefunded } \\
\text { RV Bonds }\end{array}$ \\
\hline Observations & 92,778 & 92,778 & 92,778 & 95,421 \\
\hline R-squared & 0.329 & 0.329 & 0.330 & 0.376 \\
\hline State FE & YES & YES & YES & YES \\
\hline Year FE & YES & YES & YES & YES \\
\hline Capital Purpose FE & YES & YES & YES & YES \\
\hline Initial Rating FE & YES & YES & YES & YES \\
\hline
\end{tabular}

Notes: The table above shows the coefficients from regressing each bond's average wait time, from when its call option unlocks to when it is called, on various fiscal calendar dummies. Month before FY End, FY End, and Month after FY End are dummy variables equal to one if the month that the bond's call option unlocked was the month before its state's fiscal year end, the month of the fiscal year end, or the month after the fiscal year end, respectively. Small is a dummy equal to one if the issuer borrowed fewer than five issues over our sample period. The data comes from the Mergent Bond Database and covers all municipal bonds issued with a call option, which were not advance refunded between 2001 and 2018. Columns 1 through 3 only include general obligation bonds, while column 4 only includes revenue bonds. 
Table 7. Regressions Explaining Delay Time using Proxy for Workload

(1)

DEPENDENT VARIABLE:

Num Issues Unlocked - Prev 5y Avg

Num Issues Unlocked

Prev 5y Avg of Num Issues Unlocked

\section{Control Variables}

Coupon (\%)

Offering Yield (\%)

Downgraded

Months to Maturity

Ln Size (USD)

\section{Sample}

\section{Observations}

R-squared

State FE

Year FE

Capital Purpose FE

Initial Rating FE
(2)

(3)

(4)

Avg Wait Time (Years)
$0.0191^{* * *}$
$(0.00507)$

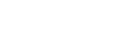

$\begin{array}{cc}0.0418 & 0.0413 \\ (0.0541) & (0.0542) \\ -0.241^{* * *} & -0.241^{* * *} \\ (0.0823) & (0.0823) \\ 0.179^{* * *} & 0.179^{* * *} \\ (0.0424) & (0.0425) \\ 0.008^{* * *} & 0.008^{* * *} \\ (0.001) & (0.001) \\ -0.133^{* * *} & -0.133^{* * *} \\ (0.0173) & (0.0171)\end{array}$

Issuers with at least

1 Bond Unlocked over Last 5 Yrs

$0.0190^{* * *}$
$(0.00511)$
$-0.0180^{* * *}$
$(0.00543)$

\section{$0.0403^{* * *}$}

(0.00944)

$$
\begin{gathered}
(0.00511) \\
-0.0180^{* * *} \\
(0.00543)
\end{gathered}
$$

\section{Issuers with at least \\ 1 Bond Unlocked over Last 5 Yrs}

$$
\begin{gathered}
0.0232 \\
(0.0596) \\
-0.215^{* *} \\
(0.0885) \\
0.192^{* * *} \\
(0.0428) \\
0.008^{* * *} \\
(0.001) \\
-0.125^{* * *} \\
(0.0188)
\end{gathered}
$$

\section{Issuers with 1-5 \\ Bonds Unlocked over Last 5 Yrs}

$0.0399^{* * *}$

$(0.00932)$

$-0.0323^{* *}$

(0.0154)

0.0223

(0.0596)

$-0.215^{* *}$

(0.0885)

$0.192^{* * *}$

(0.0428)

$0.008^{* * *}$

(0.001)

$-0.126^{* * *}$

(0.0188)

\section{Issuers with 1-5}

Bonds Unlocked over Last 5 Yrs

$\begin{array}{cc}139,076 & 139,076 \\ 0.177 & 0.177 \\ \text { YES } & \text { YES } \\ \text { YES } & \text { YES } \\ \text { YES } & \text { YES } \\ \text { YES } & \text { YES }\end{array}$

124,899

0.173

YES

YES

YES

Notes: The table above shows the coefficients from regressing each bond's average wait time, from when its call option unlocks to when it is called, on proxies for issuer workload. For each bond, in the year that its call option unlocked, Num Issues Unlocked measures the total number of bond issues from the same issuer that became currently refundable in the same year; and Prev $5 \mathrm{y} \mathrm{Avg} \mathrm{of} \mathrm{Num} \mathrm{Issues} \mathrm{Unlocked} \mathrm{measures} \mathrm{the} \mathrm{average} \mathrm{number} \mathrm{of} \mathrm{bond} \mathrm{issues}$ that became currently refundable over the previous 5 years. When the difference between these two variables is larger, it implies that the issuer had a larger number of bonds to consider than usual, resulting in a larger workload. The data comes from the Mergent Bond Database and bonds whose call option unlocked between years 2001 through 2018. 
Table 8. Explaining Delays using Underwriter Market Competition

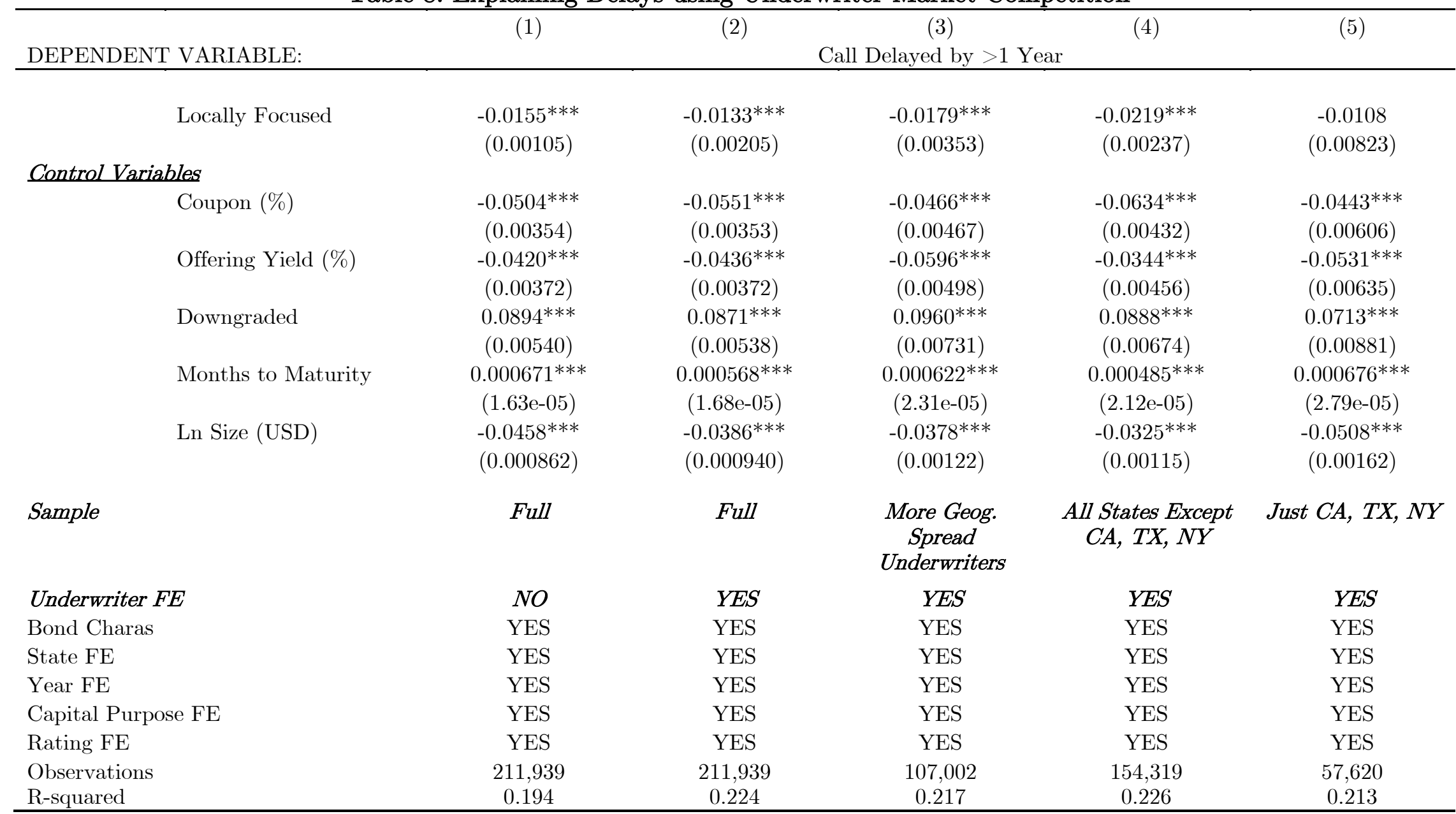

Notes: The table above shows the coefficients from regressing the decision to delay calling a bond on local underwriter focus (Locally Focused), which measures the relative competitiveness of the bond's underwriter compared to the top underwriter in the state and year. More precisely, for underwriter $\mathrm{i}$ in state s, it is calculated as: $\ln$ (amount underwritten am $_{\text {is }} \max _{j}\left\{\right.$ amount underwritten $\left._{j s}\right\}$ ), where $\mathrm{j}$ represents the set of all potential underwriters. To help interpret the magnitudes, we standardize this variable so that it has a mean of 0 and standard deviation of 1 . Columns 1 and 2 estimate the regression using the full sample; column 3 only uses the bottom 50 percentile of underwriters based upon their regional concentration; column 4 uses all states except the three largest markets: CA, TX, and NY; column 5 only uses bonds issued in CA, TX, and NY. For each underwriter, regional concentration is measured by an HHI index constructed using total volumes underwritten across each state. The sample includes all callable bonds that have not been advance refunded on the date that the bond's call option unlocks. The data comes from the Mergent Bond Database and covers all bonds with a call option that unlocked between January 1, 2001 and December 31, 2018. 
Table 9. Percent of Bonds Written by Same Lead Underwriter

All Issuers

Issuers with at least

20 bonds issued

Issuers with at least

40 bonds issued

Issuers with at least

60 bonds issued

Issuers with Bear

Stearns as top lead

underwriter

Issuers with Lehman

as top lead

underwriter

\begin{tabular}{|c|c|c|c|c|c|c|c|}
\hline \multicolumn{8}{|c|}{ \% of Total Bond Volume Underwritten by Top Lead Underwriter (2002-2007) } \\
\hline Mean & Std & Min & $25 \%$ & Median & $75 \%$ & Max & $\mathrm{N}$ \\
\hline $85.73 \%$ & $22.11 \%$ & $14.90 \%$ & $70.58 \%$ & $100 \%$ & $100 \%$ & $100 \%$ & 29,475 \\
\hline $74.43 \%$ & $24.88 \%$ & $14.90 \%$ & $53.28 \%$ & $77.32 \%$ & $100 \%$ & $100 \%$ & 13,687 \\
\hline $63.65 \%$ & $24.81 \%$ & $14.90 \%$ & $42.95 \%$ & $59.88 \%$ & $87.24 \%$ & $100 \%$ & 6,573 \\
\hline $57.77 \%$ & $24.62 \%$ & $14.90 \%$ & $37.61 \%$ & $52.51 \%$ & $76.61 \%$ & $100 \%$ & 3,709 \\
\hline $75.14 \%$ & $25.79 \%$ & $25.77 \%$ & $52.55 \%$ & $85.37 \%$ & $100 \%$ & $100 \%$ & 142 \\
\hline $77.32 \%$ & $26.45 \%$ & $21.66 \%$ & $55.40 \%$ & $91.06 \%$ & $100 \%$ & $100 \%$ & 281 \\
\hline
\end{tabular}

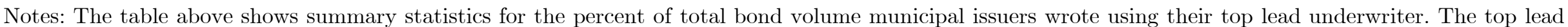

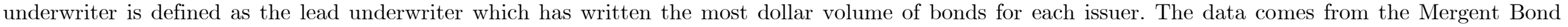
Database and covers all bonds issued between January 1, 2002 and December 31, 2007. 


\section{Table 10. Regressions Explaining Calling Delay using Underwriter Persistence}

Dummy for Delayed

\begin{tabular}{lccc} 
Underwriter Persistence & $0.0740^{* * *}$ & $0.0300^{* * *}$ & $0.0210^{* *}$ \\
& $(0.0041)$ & $(0.0041)$ & $(0.0104)$ \\
Locally Focused & & & $-0.0188^{* * *}$ \\
& & & $(0.0016)$ \\
Persistence* Locally Focused & & & $-0.0119^{* * *}$ \\
& & $(0.0047)$ \\
Control for Bond Charas & NO & YES & YES \\
State Fixed Effect & YES & YES & YES \\
Year Fixed Effect & YES & YES & YES \\
Initial Credit Score Fixed Effect & YES & YES & YES \\
Capital Purpose Fixed Effect & YES & YES & YES \\
& & & \\
Observations & 117,078 & 117,078 & 117,078 \\
R-squared & 0.184 & 0.218 & 0.220 \\
\hline
\end{tabular}

Notes: The table above shows the coefficients from regressing the decision to delay calling a bond on the bond underwriter's persistence, rank, and an interaction between persistence and rank. Underwriter persistence ranges between 0 and 1, and it measures the stickiness of the relationship between the bond's issuer and its largest underwriter. More specifically, it is calculated as the percent of all issuances by par amount that was underwritten by the lead underwriter over the last ten years, starting from the bond's call unlock date. If a bond's issuer did not issue any new bonds over the last ten years, then the bond is dropped from our sample. Locally Focused measures the competitiveness of the bond's underwriter relative to the top underwriter in the state and year. More precisely, for underwriter $\mathrm{i}$ in state $\mathrm{s}$, it is calculated as: $\ln$ (amount underwritten is $_{\text {is }}$ / $\max _{j}\left\{\right.$ amount underwritten $\left.\left._{j s}\right\}\right)$, where $\mathrm{j}$ represents the set of all potential underwriters. To help interpret the magnitudes, we standardize this variable so that it has a mean of 0 and standard deviation of 1 . The sample includes all callable bonds that have not been advance refunded on the date that the bond's call option unlocks. The data comes from the Mergent Bond Database and covers all bonds with a call option that unlocked between January 1, 2001 and December 31, 2018. 


\section{Table 11. Difference in Difference Using Fall of Lehman and Bear Stearns}

Dummy for Delayed

(1)

\begin{tabular}{lcc}
\hline Bear Stearns or Lehman Dummy & $-0.128^{* * *}$ & $-0.0947^{* * *}$ \\
& $(0.00992)$ & $(0.00951)$ \\
Year $>=2009$ Dummy & $-0.206^{* * *}$ & Absorbed \\
& $(0.00361)$ & \\
& & \\
Diff-in-Diff Interaction & $0.0368^{* *}$ & $0.0254^{*}$ \\
& $(0.0148)$ & $(0.0137)$
\end{tabular}

Goldman Sachs Dummy

Goldman Sachs Interaction

Control for Bond Charas

State FE

Year X Rating FE

Observations

Adjusted R-squared

(2) + $* * *$

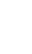

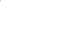




\section{Internet Appendix}

to

"Calling All Issuers: The Market for Debt Monitoring" HUAIZHI CHEN, LAUREN COHEN, and WEILING LIU 


\section{Appendix A: Additional Results}

Figure A1. Par Amount of Advance Refundings of Municipal Bonds by Year

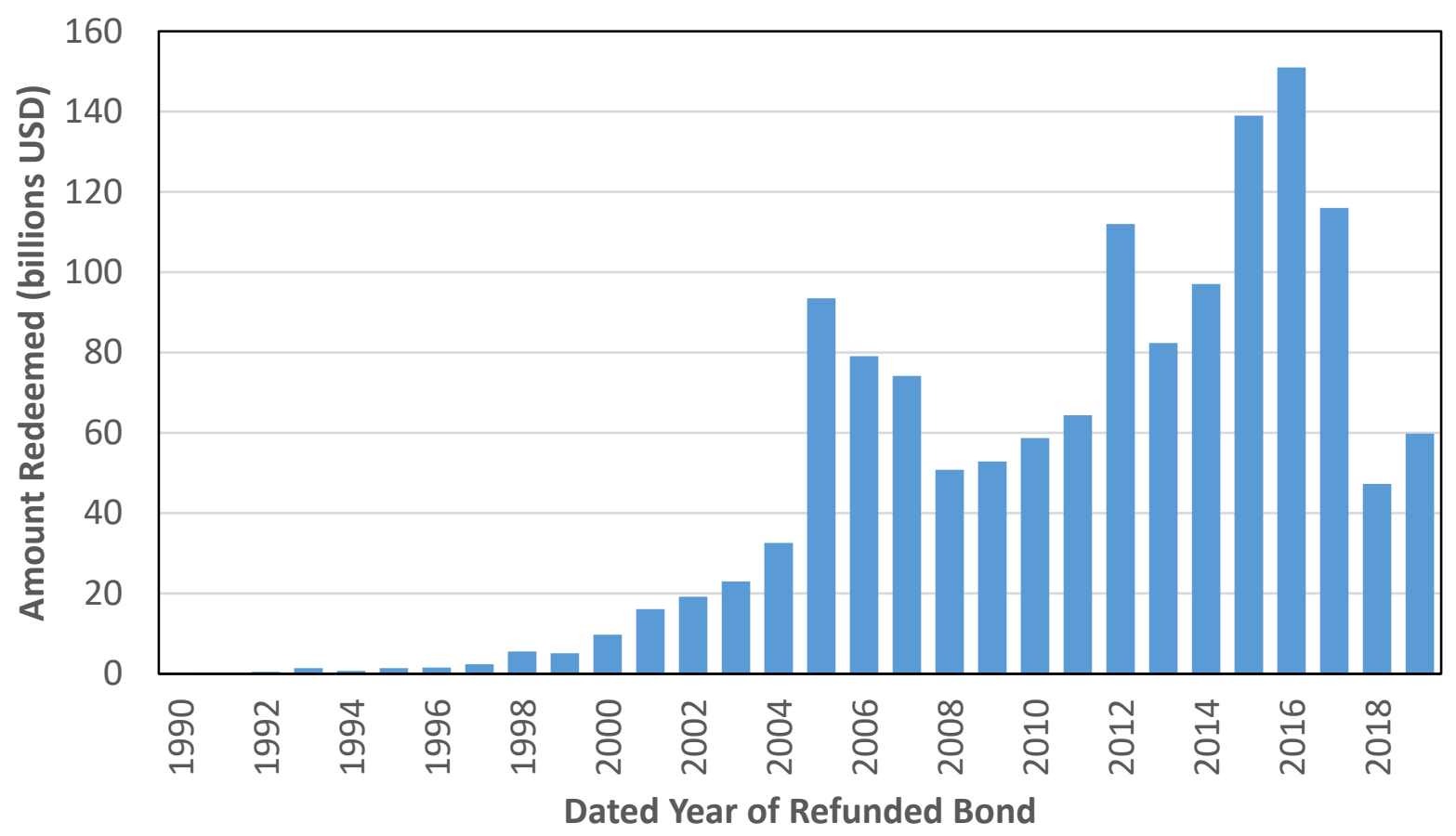

Notes: The plot above shows the annual time series of the total par amount of municipal bonds that have been advance refunded. The data comes from the Mergent Bond Database and the refunding year corresponds to the year of the dated date of the refunding bond. If no refunding bond date is provided, then the year corresponds to the call redemption year. 
Figure A2. Annual Value Lost Due to Call Delays for Various Issuance Fees

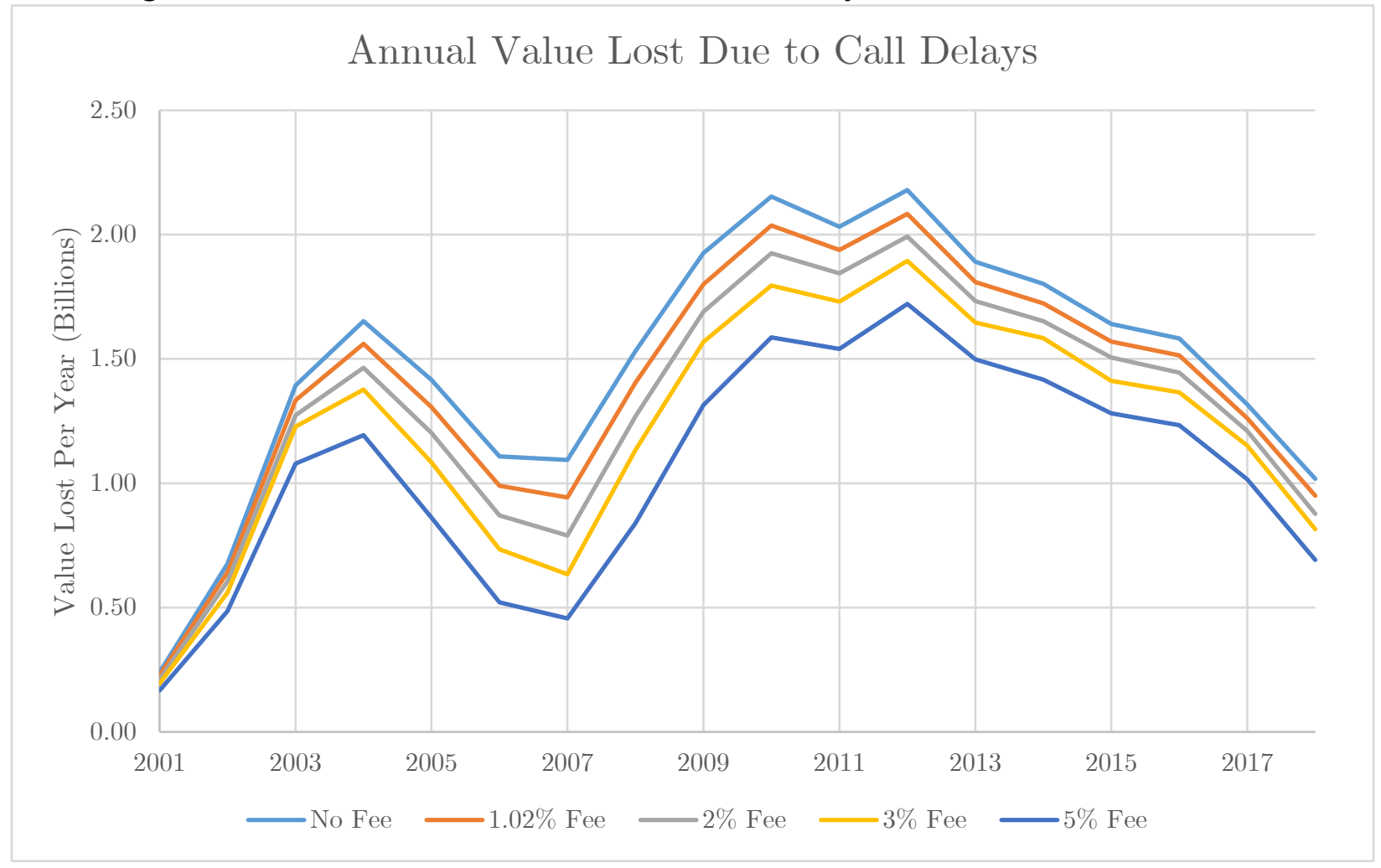

Notes: The figure above plots the estimated annual value lost by municipal bond issuers due to delays in the utilization of redemption options. The model implied value lost are considered under no fee and various fee structures, ranging from $0 \%$ of par (light blue) to $5 \%$ of par (dark blue). In the main text of the paper, we assume $1.02 \%$ fees (orange), which is the empirical estimate found in Joffe (2015). 
Table A1. Probit Regression Explaining Variation in Calling Delays

\begin{tabular}{|c|c|c|c|c|c|c|}
\hline & (1) & $(2)$ & $(3)$ & $(4)$ & $(5)$ & (6) \\
\hline & \multicolumn{6}{|c|}{ Dummy for Delayed } \\
\hline Coupon (\%) & $\begin{array}{c}-0.279^{* * *} \\
(0.017)\end{array}$ & & & & & $\begin{array}{c}-0.141^{* * *} \\
(0.027)\end{array}$ \\
\hline Offering Yield (\%) & & $\begin{array}{c}-0.266^{* * *} \\
(0.017)\end{array}$ & & & & $\begin{array}{c}-0.134^{* * *} \\
(0.029)\end{array}$ \\
\hline Downgraded & & & $\begin{array}{c}0.251^{* * *} \\
(0.055)\end{array}$ & & & $\begin{array}{c}0.266^{* * *} \\
(0.005)\end{array}$ \\
\hline Days until Maturity & & & & $\begin{array}{c}0.009^{* *} \\
(0.004)\end{array}$ & & $\begin{array}{c}0.065^{* * *} \\
(0.005)\end{array}$ \\
\hline Ln Size (USD) & & & & & $\begin{array}{c}-0.144^{* * *} \\
(0.008)\end{array}$ & $\begin{array}{c}-0.146^{* * *} \\
(0.009)\end{array}$ \\
\hline Observations & 211,942 & 211,942 & 211,942 & 211,942 & 211,942 & 211,942 \\
\hline State FE & YES & YES & YES & YES & YES & YES \\
\hline Year FE & YES & YES & YES & YES & YES & YES \\
\hline Capital Purpose FE & YES & YES & YES & YES & YES & YES \\
\hline Initial Rating FE & YES & YES & YES & YES & YES & YES \\
\hline
\end{tabular}

Notes: The table above shows the coefficients from a probit regression explaining the decision to delay calling a bond using different bond characteristics. The sample includes all callable bonds that have not been advance refunded on the date that the bond's call option unlocks. The outcome variable, Dummy for Delayed, is equal to one if the bond was called at least one year after its call option unlocked, or it was never called. Explanatory bond characteristics include: the coupon rate, the listed offering yield, a dummy for whether the bond was downgraded since issuance, the number of days remaining from the date the call option unlocked until maturity, and the natural log of the issuance par size. In addition, we add fixed effects for state, year, capital purpose, and the initial credit rating of the issuer. The data comes from the Mergent Bond Database and covers all bonds with a call option that unlocked between January 1, 2001 and December 31, 2018. 
Table A2. Bond Characteristics Explaining Variation in Advance Refundings

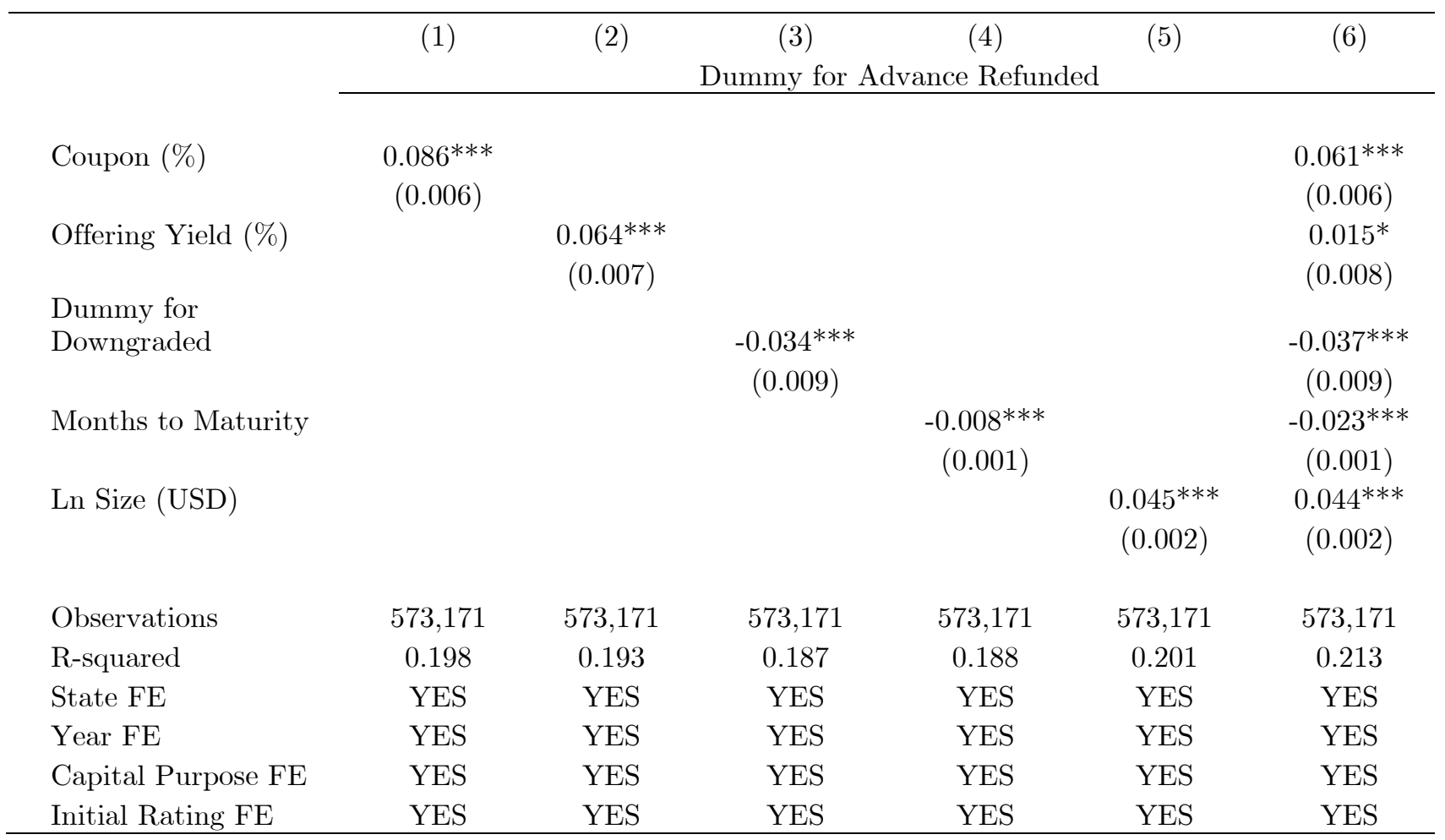

Notes: The table above shows the coefficients from regressing the decision to advance refund a bond on various bond characteristics. The sample includes all callable bonds. Explanatory bond characteristics include: the coupon rate, the listed offering yield, a dummy for whether the bond was downgraded since issuance, the number of days remaining from the date the call option unlocked until maturity, and the natural $\log$ of the issuance par size. In addition, we add fixed effects for state, year, capital purpose, and the initial credit rating of the issuer. The data comes from the Mergent Bond Database and covers all bonds with a call option that unlocked between January 1, 2001 and December 31, 2018. 
(1)

(2)

Dummy for Delayed

\begin{tabular}{|c|c|c|c|}
\hline \multirow[b]{2}{*}{ Max Call Price } & \multicolumn{3}{|c|}{$\begin{array}{c}(2) \\
\text { Dummy for Delayed }\end{array}$} \\
\hline & $\begin{array}{c}0.00930^{* *} \\
(0.00419)\end{array}$ & & $\begin{array}{c}0.00401 \\
(0.00367)\end{array}$ \\
\hline Dummy for Non-par Call Price & & $\begin{array}{c}0.0320^{* * *} \\
(0.0112)\end{array}$ & $\begin{array}{c}0.0531^{* * *} \\
(0.0124)\end{array}$ \\
\hline Coupon $(\%)$ & & & $\begin{array}{c}-0.0526^{* * *} \\
(0.00915)\end{array}$ \\
\hline Offering Yield (\%) & & & $\begin{array}{c}-0.0413^{* * *} \\
(0.00972)\end{array}$ \\
\hline Downgraded & & & $\begin{array}{c}0.0874^{* * *} \\
(0.0182)\end{array}$ \\
\hline Days to Maturity & & & $\begin{array}{c}0.0202^{* * *} \\
(0.0014)\end{array}$ \\
\hline Ln Size (USD) & & & $\begin{array}{c}-0.0487^{* * *} \\
(0.00281)\end{array}$ \\
\hline Observations & 211,942 & 211,942 & 211,942 \\
\hline R-squared & 0.161 & 0.162 & 0.195 \\
\hline State FE & YES & YES & YES \\
\hline Year FE & YES & YES & YES \\
\hline Capital Purpose FE & YES & YES & YES \\
\hline Initial Rating FE & YES & YES & YES \\
\hline
\end{tabular}

Notes: The table above shows the coefficients from a regression explaining the decision to delay calling a bond using the price at call. The sample includes all callable bonds that have not been advance refunded on the date that the bond's call option unlocks. The key explanatory variables are "Max Call Price," which is the highest possible call price ( also equal to the call price when the bond is first able to be called), and "Dummy for Non-par Call Price," which is a dummy variable equal to one if the bond has a call price which is not equal to par. The outcome variable, Dummy for Delayed, is equal to one if the bond was called at least one year after its call option unlocked, or it was never called. Other explanatory bond characteristics include: the coupon rate, the listed offering yield, a dummy for whether the bond was downgraded since issuance, the number of days remaining from the date the call option unlocked until maturity, and the natural log of the issuance par size. In addition, we add fixed effects for state, year, capital purpose, and the initial credit rating of the issuer. The data comes from the Mergent Bond Database and covers all bonds with a call option that unlocked between January 1, 2001 and December 31, 2018. 
Table A4. Summary Statistics by Credit Rating, including Unrated Bonds

\begin{tabular}{|c|c|c|c|c|c|c|}
\hline Rating & $\begin{array}{l}\text { Total Size } \\
\text { (bil USD) }\end{array}$ & $\begin{array}{l}\mathrm{p} 25 \\
\text { Delayed }\end{array}$ & $\begin{array}{l}\mathrm{p} 50 \\
\text { Delayed }\end{array}$ & $\begin{array}{l}\text { p75 } \\
\text { Delayed }\end{array}$ & $\begin{array}{l}\text { \% Delay } \\
\text { Year+ }\end{array}$ & $\%$ Never Call \\
\hline Unrated & 708.63 & 0.00 & 0.64 & 9.46 & 25.35 & 15.24 \\
\hline AAA & 454.69 & 0.07 & 1.00 & 4.15 & 25.24 & 9.92 \\
\hline AA & 797.52 & 0.00 & 0.32 & 1.39 & 13.38 & 6.34 \\
\hline A & 221.00 & 0.00 & 0.61 & 2.15 & 24.34 & 9.06 \\
\hline $\mathrm{BBB}$ & 61.60 & 0.08 & 0.92 & 3.08 & 31.55 & 10.31 \\
\hline $\mathrm{BB}$ & 8.01 & 0.63 & 1.91 & 4.62 & 63.19 & 21.99 \\
\hline B & 10.34 & 1.79 & 3.84 & 7.15 & 75.00 & 22.95 \\
\hline $\mathrm{CCC}$ & 2.09 & 2.08 & 4.17 & 30.42 & 81.82 & 36.36 \\
\hline
\end{tabular}

Notes: The table above summarizes bond characteristics and calling behavior by credit rating at the time the call option unlocked and whether the bond experienced a credit downgrade since issuance. Columns 3-5 reports the 25th, 50th, and 75th percentiles for the number of years between when a bond's call option is unlocked and when the bond is called, Column 6 shows the percent of all bonds which waited at least one year to call, and Column 7 shows the percent of all bonds which never called. The data comes from the Mergent Bond Database and covers all bonds with a call option that unlocked between January 1, 2001 and December 31, 2018. Ratings data comes from Capital IQ s Standard and Poor ratings database. 
Table A5. Summary Statistics for California Fee Dataset

\begin{tabular}{|c|c|c|c|c|c|c|}
\hline Variable & Num Obs & Mean & Median & Std. Dev. & Min & $\operatorname{Max}$ \\
\hline Total issuance cost (\% of principal) & 3,562 & 1.31 & 1.99 & 2.50 & 0.01 & 14.97 \\
\hline Issuance Size (mil USD) & 3,562 & 168.67 & 10.50 & 60.30 & 0.04 & $2,100.00$ \\
\hline Maximum Maturity (years) & 3,562 & 25.72 & 25.00 & 5.32 & 1.00 & 40.00 \\
\hline Dummy for Negotiated Bid & 3,562 & 0.73 & 1.00 & 0.46 & 0.00 & 1.00 \\
\hline Dummy for Use of Adviser & 3,562 & 0.85 & 1.00 & 0.39 & 0.00 & 1.00 \\
\hline Dummy for Insured & 3,562 & 0.52 & 1.00 & 0.47 & 0.00 & 1.00 \\
\hline
\end{tabular}

Notes: The table above shows summary statistics (number of observations, value-weighted mean, median, standard deviation, minimum, and maximum) for key variables from the public bond issuance dataset provided by the state of California. Total issuance costs include the following categories: underwriter fee, advising fee, legal counsel fee, guarantees, and other. Our dataset covers all bonds issued and disclosed by the state of California between years 1990 and 2020. 
Table A6. Hedonic Cost Regression Using California Fee Data

\begin{tabular}{cccc}
\hline & $(1)$ & $(2)$ & $(3)$ \\
Dependent Variable: & & Total Issuance Costs (\% of Par) & \\
Ln principal amt & $-1.348^{* * *}$ & $-1.347^{* * *}$ & $-1.266^{* * *}$ \\
& $(0.024)$ & $(0.024)$ & $(0.026)$ \\
Dummy for insured & $0.637^{* * *}$ & $0.458^{* *}$ & $0.468^{* * *}$ \\
& $(0.082)$ & $(0.182)$ & $(0.181)$ \\
Dummy for advised & $0.687^{* * *}$ & $0.677^{* * *}$ & $0.709^{* * *}$ \\
& $(0.083)$ & $(0.083)$ & $(0.083)$ \\
Dummy for callable & $-0.299^{* * *}$ & $-0.315^{* * *}$ & $-0.337^{* * *}$ \\
& $(0.086)$ & $(0.086)$ & $(0.085)$ \\
Dummy for negotiated bid & $0.833^{* * *}$ & $0.815^{* * *}$ & $0.728^{* * *}$ \\
& $(0.070)$ & $(0.070)$ & $(0.071)$ \\
Max maturity within issue & $0.035^{* * *}$ & $0.036^{* * *}$ & $0.029^{* * *}$ \\
Proxy for experience of issuer & $(0.005)$ & $(0.005)$ & $(0.006)$ \\
Year FEs & & & $-0.322^{* * *}$ \\
Rating FEs & & & $(0.046)$ \\
Rating x Insured FEs & YES & YES & YES \\
Observations & NO & NO & YES \\
R-squared & 3,472 & 3,472 & 3,472 \\
& 0.198 & 0.199 & 0.202 \\
\hline
\end{tabular}

Notes: The table above shows coefficients from a hedonic cost regression that explains total issuance costs (as percent of par amount) using observable bond characteristics. Each observation is one bond issue. Total issuance costs include the following categories: underwriter fee, advising fee, legal counsel fee, guarantees, and other. The max maturity is calculated by taking the largest maturity bond within the issue; and the experience of the issuer is approximated by using the log number of issues sold per year. This dataset covers all bonds issued and disclosed by the state of California between years 1990 and 2020 . 
Table A7. Explaining Delays using Underwriter Market Competition and Bid Type

\begin{tabular}{|c|c|c|c|c|c|}
\hline \multirow[b]{2}{*}{ DEPENDENT VARIABLE: } & $(1)$ & $(2)$ & $(3)$ & $(4)$ & $(5)$ \\
\hline & \multicolumn{5}{|c|}{ Call Delayed by $>1$ Year } \\
\hline Locally Focused & $\begin{array}{c}-0.008^{* * *} \\
(0.001)\end{array}$ & $\begin{array}{c}-0.007^{* *} \\
(0.001)\end{array}$ & $\begin{array}{c}-0.011^{* * *} \\
(0.002)\end{array}$ & $\begin{array}{c}-0.012^{* * *} \\
(0.001)\end{array}$ & $\begin{array}{l}-0.005 \\
(0.004)\end{array}$ \\
\hline \multicolumn{6}{|l|}{ Control Variables } \\
\hline Negotiated Bid & $\begin{array}{c}0.019^{* * *} \\
(0.001)\end{array}$ & $\begin{array}{c}0.011^{* * *} \\
(0.001)\end{array}$ & $\begin{array}{l}0.007^{*} \\
(0.002)\end{array}$ & $\begin{array}{c}0.016^{* * *} \\
(0.001)\end{array}$ & $\begin{array}{c}0.005 \\
(0.004)\end{array}$ \\
\hline Coupon (\%) & $\begin{array}{c}-0.052^{* * *} \\
(0.003)\end{array}$ & $\begin{array}{c}-0.056^{* * *} \\
(0.004)\end{array}$ & $\begin{array}{c}-0.046^{* * *} \\
(0.005)\end{array}$ & $\begin{array}{c}-0.064^{* * *} \\
(0.005)\end{array}$ & $\begin{array}{c}-0.044^{* * *} \\
(0.006)\end{array}$ \\
\hline Offering Yield (\%) & $\begin{array}{c}-0.042^{* * *} \\
(0.004)\end{array}$ & $\begin{array}{c}-0.043^{* * *} \\
(0.004)\end{array}$ & $\begin{array}{c}-0.060^{* * *} \\
(0.005)\end{array}$ & $\begin{array}{c}-0.034^{* * *} \\
(0.005)\end{array}$ & $\begin{array}{c}-0.053^{* * *} \\
(0.006)\end{array}$ \\
\hline Downgraded & $\begin{array}{c}0.090^{* * * *} \\
(0.005)\end{array}$ & $\begin{array}{c}0.087^{* * *} \\
(0.005)\end{array}$ & $\begin{array}{c}0.096^{* * *} \\
(0.007)\end{array}$ & $\begin{array}{c}0.089^{* * *} \\
(0.007)\end{array}$ & $\begin{array}{c}0.071^{* * *} \\
(0.008)\end{array}$ \\
\hline Months to Maturity & $\begin{array}{l}0.001^{* * *} \\
(0.0002)\end{array}$ & $\begin{array}{c}0.001^{* * *} \\
(0.0002)\end{array}$ & $\begin{array}{l}0.001^{* * *} \\
(0.00002)\end{array}$ & $\begin{array}{l}0.001^{* * *} \\
(0.00002)\end{array}$ & $\begin{array}{l}0.001^{* * *} \\
(0.00003)\end{array}$ \\
\hline Ln Size (USD) & $\begin{array}{c}-0.046^{* * *} \\
(0.001)\end{array}$ & $\begin{array}{c}-0.039^{* * *} \\
(0.001)\end{array}$ & $\begin{array}{c}-0.037^{* * *} \\
(0.001)\end{array}$ & $\begin{array}{c}-0.033^{* * *} \\
(0.001)\end{array}$ & $\begin{array}{c}-0.051^{* * *} \\
(0.002)\end{array}$ \\
\hline Sample & Full & Full & $\begin{array}{c}\text { More Geog. Spread } \\
\text { Underwriters }\end{array}$ & $\begin{array}{l}\text { All States Except } \\
\quad C A, T X, N Y\end{array}$ & Just $C A, T X, N Y$ \\
\hline Underwriter $F E$ & NO & $Y E S$ & $Y E S$ & $Y E S$ & $Y E S$ \\
\hline Bond Charas & YES & YES & YES & YES & YES \\
\hline State FE & YES & YES & YES & YES & YES \\
\hline Year FE & YES & YES & YES & YES & YES \\
\hline Capital Purpose FE & YES & YES & YES & YES & YES \\
\hline Rating FE & YES & YES & YES & YES & YES \\
\hline Observations & 211,939 & 211,939 & 107,002 & 154,319 & 57,620 \\
\hline R-squared & 0.194 & 0.224 & 0.217 & 0.226 & 0.213 \\
\hline
\end{tabular}

Notes: The table above shows the coefficients from Table 8, including a new dummy Negotiated Bid, which equals one when the bond was sold through a negotiated bid rather than private placement or competitive auction. The main explanatory variable is local underwriter focus (Locally Focused), which measures the relative competitiveness of the bond's underwriter compared to the top underwriter in the state and year. Columns 1 and 2 estimate the regression using the full sample; column 3 only uses the bottom 50 percentile of underwriters based upon their regional concentration; column 4 uses all states except the three largest markets: CA, TX, and NY; column 5 only uses bonds issued in CA, TX, and NY. For each underwriter, regional concentration is measured by an HHI index constructed using total volumes underwritten across each state. The sample includes all callable bonds that have not been advance refunded on the date that the bond's call option unlocks. The data comes from the Mergent Bond Database and covers all bonds with a call option that unlocked between January 1 , 2001 and December 31, 2018. 
Table A8. Explaining Delay using Fiscal Calendar: Not Bank-Qualified Issuers Only

\begin{tabular}{|c|c|c|c|c|}
\hline & (1) & $(2)$ & $(3)$ & (4) \\
\hline DEPENDENT VARIABLES: & \multicolumn{4}{|c|}{ Avg Wait Time (Yrs) } \\
\hline Month before FY End & $\begin{array}{l}-0.184 \\
(0.158)\end{array}$ & & $\begin{array}{l}-0.182 \\
(0.168)\end{array}$ & $\begin{array}{l}-0.0707 \\
(0.135)\end{array}$ \\
\hline FY End & $\begin{array}{c}0.180^{* * *} \\
(0.0693)\end{array}$ & & $\begin{array}{l}0.172^{* *} \\
(0.0818)\end{array}$ & $\begin{array}{l}-0.150 \\
(0.102)\end{array}$ \\
\hline Month after FY End & $\begin{array}{c}0.0461 \\
(0.0660)\end{array}$ & & $\begin{array}{c}0.0538 \\
(0.0804)\end{array}$ & $\begin{array}{l}0.00346 \\
(0.0562)\end{array}$ \\
\hline Dummy for Small Issuer & & $\begin{array}{c}0.0801^{* * * *} \\
(0.0292)\end{array}$ & $\begin{array}{c}0.0818^{* * *} \\
(0.0307)\end{array}$ & \\
\hline \multicolumn{5}{|l|}{ Interaction Terms } \\
\hline Small * Month before FY End & & & $\begin{array}{c}0.137 \\
(0.264)\end{array}$ & \\
\hline Small * FY End & & & $\begin{array}{c}0.107 \\
(0.267)\end{array}$ & \\
\hline Small * Month after FY End & & & $\begin{array}{l}-0.0341 \\
(0.128)\end{array}$ & \\
\hline \multicolumn{5}{|l|}{ Control Variables } \\
\hline Coupon $(\%)$ & $\begin{array}{l}-0.0210 \\
(0.0390)\end{array}$ & $\begin{array}{l}-0.0177 \\
(0.0397)\end{array}$ & $\begin{array}{l}-0.0222 \\
(0.0392)\end{array}$ & $\begin{array}{c}-0.00886 \\
(0.0419)\end{array}$ \\
\hline Offering Yield (\%) & $\begin{array}{l}-0.0178 \\
(0.0416)\end{array}$ & $\begin{array}{l}-0.0239 \\
(0.0422)\end{array}$ & $\begin{array}{l}-0.0211 \\
(0.0419)\end{array}$ & $\begin{array}{c}0.0355 \\
(0.0418)\end{array}$ \\
\hline Downgraded & $\begin{array}{c}0.208^{* * *} \\
(0.0724)\end{array}$ & $\begin{array}{c}0.203^{* * *} \\
(0.0720)\end{array}$ & $\begin{array}{c}0.210^{* * *} \\
(0.0722)\end{array}$ & $\begin{array}{l}0.148^{* *} \\
(0.0699)\end{array}$ \\
\hline Months to Maturity & $\begin{array}{c}0.00537^{* * *} \\
(0.000389)\end{array}$ & $\begin{array}{c}0.00541^{* * *} \\
(0.000389)\end{array}$ & $\begin{array}{c}0.00538^{* * *} \\
(0.000389)\end{array}$ & $\begin{array}{c}0.00700^{* * *} \\
(0.000406)\end{array}$ \\
\hline Ln Size (USD) & $\begin{array}{c}-0.0519 * * * \\
(0.0143)\end{array}$ & $\begin{array}{c}-0.0485^{* * *} \\
(0.0144)\end{array}$ & $\begin{array}{c}-0.0494^{* * *} \\
(0.0144)\end{array}$ & $\begin{array}{c}-0.0738^{* * *} \\
(0.0116)\end{array}$ \\
\hline Sample & $\begin{array}{c}\text { Non- } \\
\text { prerefunded } \\
\text { GO Bonds }\end{array}$ & $\begin{array}{c}\text { Non- } \\
\text { prerefunded } \\
\text { GO Bonds }\end{array}$ & $\begin{array}{l}\text { Non- } \\
\text { prerefunded } \\
\text { GO Bonds }\end{array}$ & $\begin{array}{l}\text { Non-prerefunded } \\
\text { RV Bonds }\end{array}$ \\
\hline Observations & 45,062 & 45,062 & 45,062 & 76,245 \\
\hline R-squared & 0.263 & 0.263 & 0.264 & 0.369 \\
\hline State FE & YES & YES & YES & YES \\
\hline Year FE & YES & YES & YES & YES \\
\hline Capital Purpose FE & YES & YES & YES & YES \\
\hline Initial Rating FE & YES & YES & YES & YES \\
\hline
\end{tabular}

Notes: The table above repeats the regression Table 6 using only issuers who are not bank-qualified. Month before FY End, FY End, and Month after FY End are dummy variables equal to one if the month that the bond's call option unlocked was the month before its state's fiscal year end, the month of the fiscal year end, or the month after the fiscal year end, respectively. Small is a dummy equal to one if the issuer borrowed fewer than five issues over our sample period. The data comes from the Mergent Bond Database and covers all municipal bonds issued with a call option, which were not advance refunded between 2001 and 2018. Columns 1 through 3 only include general obligation bonds, while column 4 only includes revenue bonds. 
Table A9. Explaining Delay Time using Workload: Not Bank-Qualified Issuers Only

\begin{tabular}{|c|c|c|c|c|}
\hline \multirow{2}{*}{$\begin{array}{l}\text { DEPENDENT VARIABLE: } \\
\text { Num Issues Unlocked - Prev 5y Avg }\end{array}$} & \multicolumn{4}{|c|}{ Avg Wait Time (Years) } \\
\hline & $\begin{array}{c}0.0145^{* * *} \\
(0.00460)\end{array}$ & & $\begin{array}{c}0.0326^{* * *} \\
(0.00886)\end{array}$ & \\
\hline Num Issues Unlocked & & $\begin{array}{c}0.0148^{* * *} \\
(0.00417)\end{array}$ & & $\begin{array}{c}0.0340^{* * * *} \\
(0.00886)\end{array}$ \\
\hline Prev 5y Avg of Num Issues Unlocked & & $\begin{array}{c}-0.0191^{* * *} \\
(0.00500)\end{array}$ & & $\begin{array}{c}-0.0571^{* * *} \\
(0.0180)\end{array}$ \\
\hline \multicolumn{5}{|l|}{ Control Variables } \\
\hline Coupon $(\%)$ & $\begin{array}{c}0.101^{*} \\
(0.0565)\end{array}$ & $\begin{array}{c}0.101^{*} \\
(0.0565)\end{array}$ & $\begin{array}{c}0.0945 \\
(0.0630)\end{array}$ & $\begin{array}{c}0.0967 \\
(0.0631)\end{array}$ \\
\hline Offering Yield (\%) & $\begin{array}{c}-0.366^{* * *} \\
(0.111)\end{array}$ & $\begin{array}{c}-0.365^{* * *} \\
(0.110)\end{array}$ & $\begin{array}{c}-0.349^{* * *} \\
(0.121)\end{array}$ & $\begin{array}{c}-0.350^{* * *} \\
(0.121)\end{array}$ \\
\hline Downgraded & $\begin{array}{c}0.178^{* * *} \\
(0.0473)\end{array}$ & $\begin{array}{c}0.180 * * * \\
(0.0477)\end{array}$ & $\begin{array}{c}0.201^{* * *} \\
(0.0512)\end{array}$ & $\begin{array}{c}0.201^{* * *} \\
(0.0513)\end{array}$ \\
\hline Months to Maturity & $\begin{array}{c}0.00983^{* * *} \\
(0.00117)\end{array}$ & $\begin{array}{c}0.00982^{* * *} \\
(0.00117)\end{array}$ & $\begin{array}{c}0.0102^{* * *} \\
(0.00129)\end{array}$ & $\begin{array}{c}0.0102^{* * *} \\
(0.00129)\end{array}$ \\
\hline Ln Size (USD) & $\begin{array}{c}-0.204^{* * *} \\
(0.0285)\end{array}$ & $\begin{array}{c}-0.203^{* * *} \\
(0.0283)\end{array}$ & $\begin{array}{c}-0.203^{* * *} \\
(0.0313)\end{array}$ & $\begin{array}{c}-0.201^{* * *} \\
(0.0308)\end{array}$ \\
\hline Sample & $\begin{array}{c}\text { Issuers with at least } 1 \\
\text { Bond Unlocked over } \\
\text { Last } 5 \text { Yrs }\end{array}$ & $\begin{array}{l}\text { Issuers with at least } 1 \\
\text { Bond Unlocked over } \\
\text { Last } 5 \text { Yrs }\end{array}$ & $\begin{array}{l}\text { Issuers with 1-5 } \\
\text { Bonds Unlocked } \\
\text { over Last } 5 \text { Yrs }\end{array}$ & $\begin{array}{l}\text { Issuers with 1-5 } \\
\text { Bonds Unlocked } \\
\text { over Last } 5 \text { Yrs }\end{array}$ \\
\hline Observations & 98,600 & 98,600 & 85,014 & 85,014 \\
\hline R-squared & 0.198 & 0.198 & 0.198 & 0.198 \\
\hline State FE & YES & YES & YES & YES \\
\hline Year FE & YES & YES & YES & YES \\
\hline Capital Purpose FE & YES & YES & YES & YES \\
\hline Initial Rating FE & YES & YES & YES & YES \\
\hline
\end{tabular}

Notes: The table above shows the coefficients from Table 7 but restricted to the sample of issuers who are not bank-qualified. For each bond, in the year that its call option unlocked, Num Issues Unlocked measures the total number of bond issues from the same issuer that became currently refundable in the same year; and Prev $5 \mathrm{y} A \mathrm{vg}$ of Num Issues Unlocked measures the average number of bond issues that became currently refundable over the previous 5 years. When the difference between these two variables is larger, it implies that the issuer had a larger number of bonds to consider than usual, resulting in a larger workload. The data comes from the Mergent Bond Database and bonds whose call option unlocked between years 2001 through 2018. 


\section{Table A10. Bond Characteristics Explaining Variation in Calling Delays, Removing Bloomberg Discrepancies}

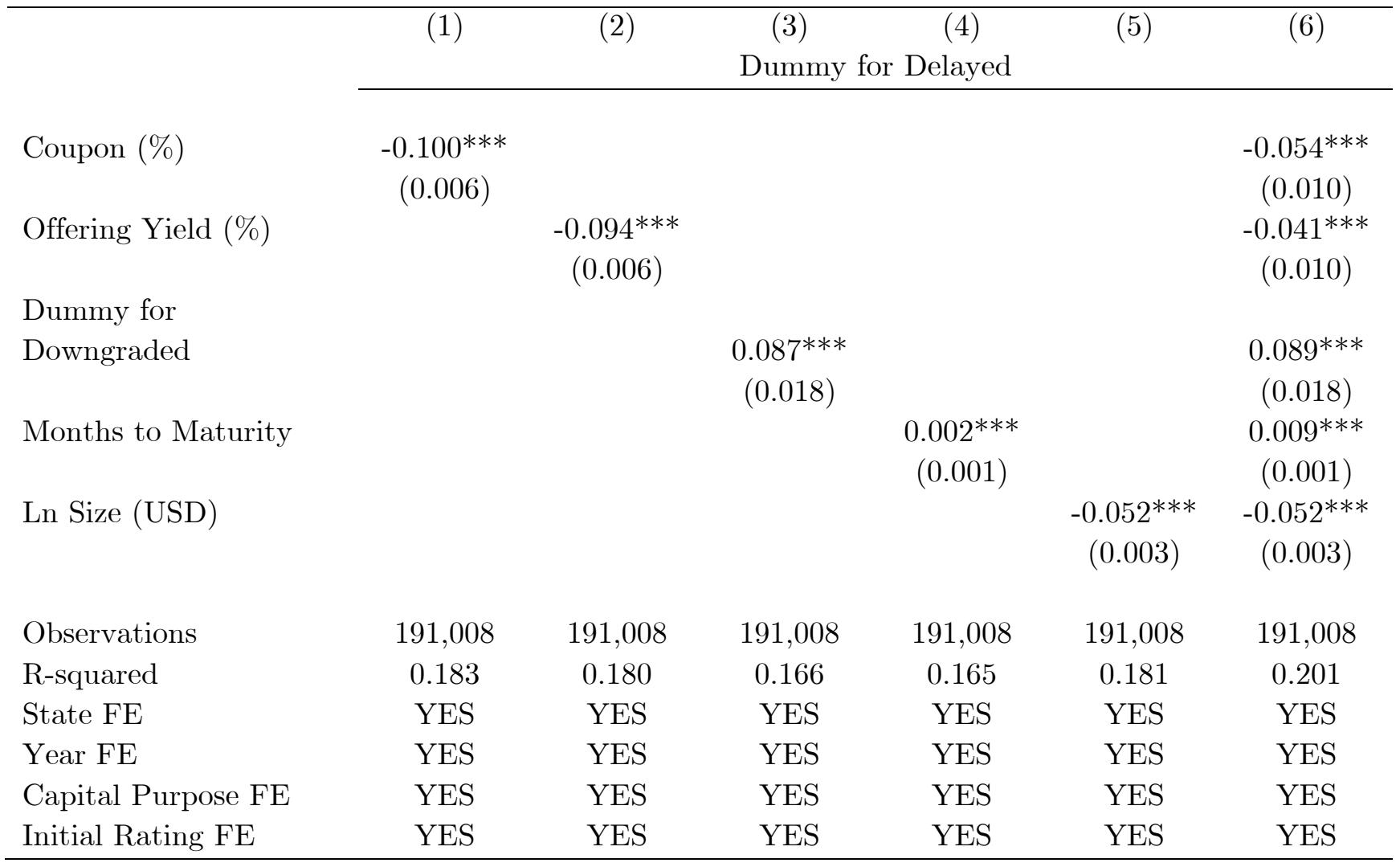

Notes: The table above shows the coefficients from regressing the decision to delay calling a bond on different bond characteristics. The sample includes all callable bonds that have not been advance refunded on the date that the bond's call option unlocks, and it removes any bond issues that were reportedly called in Bloomberg but not called in Mergent. The outcome variable, Dummy for Delayed, is equal to one if the bond was called at least one year after its call option unlocked, or it was never called. Explanatory bond characteristics include: the coupon rate, the listed offering yield, a dummy for whether the bond was downgraded since issuance, the number of days remaining from the date the call option unlocked until maturity, and the natural log of the issuance par size. In addition, we add fixed effects for state, year, capital purpose, and the initial credit rating of the issuer. The data comes from the Mergent Bond Database and covers all bonds with a call option that unlocked between January 1, 2001 and December 31, 2018. 


\section{Appendix B: Description of the Value-Lost Estimation Method}

This section describes the value-lost estimation method employed in the study in detail. As mentioned in the main text, a callable bond can be analyzed as an otherwise identical non-callable bond with an American Call Option granted to the issuer. To see this, consider a hypothetical coupon paying bond with the option to redeem at par: the issuer receives the offering price at the beginning of the bond issue and promises to pay coupon payments to the investors until the maturity date or when the issuer chooses to exercise the early redemption option. If redeemed at a date prior to maturity, the issuer can reissue the same exact coupon cashflows remaining in issue under the concurrent market conditions. If the market interest rate for these cash flows is below the bond's coupon rate, then the re-issuance price of these cashflows will be at a premium to the par value. The issuer will capture this premium at the cost of exercising the call.

Therefore, at any moment when a bond is callable, its issuer faces the question of whether to capture an immediate exercise value or retain the option for future redemptions. The issuer should only exercise early redemption if the immediate exercise value is higher than the market value of the option assuming non-exercise. While American Options typically can be exercised at any date after they are unlocked, for computational tractability, we discretize the exercise dates to every 6 -month period, which matches the semi-annual coupon payment rates of a typical municipal bond.

Specifically, for each callable bond outstanding in the beginning January of each year, we observe whether it is called by the issuer within the next 6 and 12 months. The value lost to not calling in each of the 6 -month period is calculated as the positive difference between the immediate exercise value and the current estimated value of the call option knowing that it will not be exercised in the next 6 months. The accumulated interest is treated as zero assuming the last coupon has just been paid out. This allows us to calculate the time value of the delay. The algorithm is as follows:

1) At each 6-months period, we calculate the immediate exercise value of all outstanding callable bonds using the yields of non-callable municipal bonds of similar composite credit rating category (AAA, AA, etc.) and similar remaining maturity during this period. 
For example, if a call-at-par $5 \%$ coupon AA bond with $\$ 1,000$ of principal values has 5 years left in its maturity, and we observe that non-callable 5-year $5 \%$ coupon AA bonds are issued with yields that imply values of $\$ 1,250$ dollars, then the exercise value is $\$ 250$ dollars. That is, if the original issuer calls the bond and reissue the same cash flows in the same period, it would obtain $\$ 250$ dollars from the exercise. Additionally, we can compensate for issuance fees in the exercise value. Assuming a 1.02\% of par issuance fee, the exercise value will be $\$ 1,250-\$ 1,010.2$, which is $\$ 239.8$.

2) This exercise value trades off against the value of the call option. If it is optimal to exercise, then the call option value is the exercise value. The value lost from delays is the exercise value of the call option minus the value of the option if it doesn't get exercised, i.e. its continuation value. Since we directly observe that these bonds were not called over the next 6 month period, we calculate continuation value as the current value of an American call-option that can be exercised starting in 6 months (and every 6 months until maturity). If the current value of the American call-option is equal or higher than the exercise value, then we record a 0 value due to the delay. However, if the exercise value is higher than the option value, then a value lost is the exercise value minus the continuation value. Specifically:

Value Lost $=\operatorname{Max}(0$, Exercise Value - Option Value Assuming Continuation $)$

In order to calculate the option value, for simplicity, in our baseline simulation, we assume a random walk Merton model for the market short-rate:

$$
r_{t}=r_{t-1}+\alpha+\sigma \epsilon, \quad \epsilon \sim N(0,1)
$$

Under the assumption that $r_{t}$ can never be below zero. We calibrate this model for every 6 -month interval using the parameters $\alpha=0$ and $\sigma=0.33 \%$. (The semi-annual realized standard deviation of ten-year muni yields was about 30 basis. The average options-implied volatility from the newly callable bonds is 
about 10 to 20 basis points.) We follow the simulation-regression methodology outlined in Longstaff and Schwartz (2001) for the evaluation of the model implied option values in the baseline no fee model and one with $1.02 \%$ issuance fees.

Table B1 summarizes the exercise values, continuation values, and the 6-month delay value lost for each individual callable bond that were not called starting each year.

As an example, in Figure B1, we plot the difference between the 6-month continuation value and the exercise value of the 10-year callable bond in blue, and we plot the difference between option value and exercise value in red. If current rates are high, then it is optimal to not exercise the option. In this case, the value of the option is the continuation value, and the issuer should wait to call. On the other hand, when rates are low and the exercise value is sufficiently high, then the option value is the exercise value- it is advantageous to exercise immediately over waiting 6 months. In such cases when the exercise value exceeds the continuation value, then the issuer would lose part of the premium gained from exercising if it delays by 6 months. The dashed blue line represents the 6 -month value lost when the issuer neglects optimal bond calls.

We can calculate the optimal exercise regions for a range of different remaining length to maturity, current market issuance rates for similar securities, and coupon rates. Figure B2 shows the two-dimensional optimal exercise region for 5\% semi-annual coupon bonds in yellow. In the main study, we generate this surface for a cube of maturities, market rates, and coupon rates, and we match it to the empirical data using the current market short muni-rates.

We plot the sum of the value-lost from yearly redemption delays of investment grade municipal bonds in Figure 2 assuming a 1.02\% reissuance fee structure.

Alternatively, we can utilize a more sophisticated interest rate model. Figure B3 contrasts the yearly total implied value lost by the sum of all municipal issuers utilizing a multi-factor Longstaff-Schwartz interest rate model. The results in the calibration is 
similar to our baseline results. See the figure description of the parameters utilized for the Longstaff-Schwartz model. 
Figure B1. Model-Implied Option Value for a 10 Year, 5\% Coupon Bond Time Value of Call Option

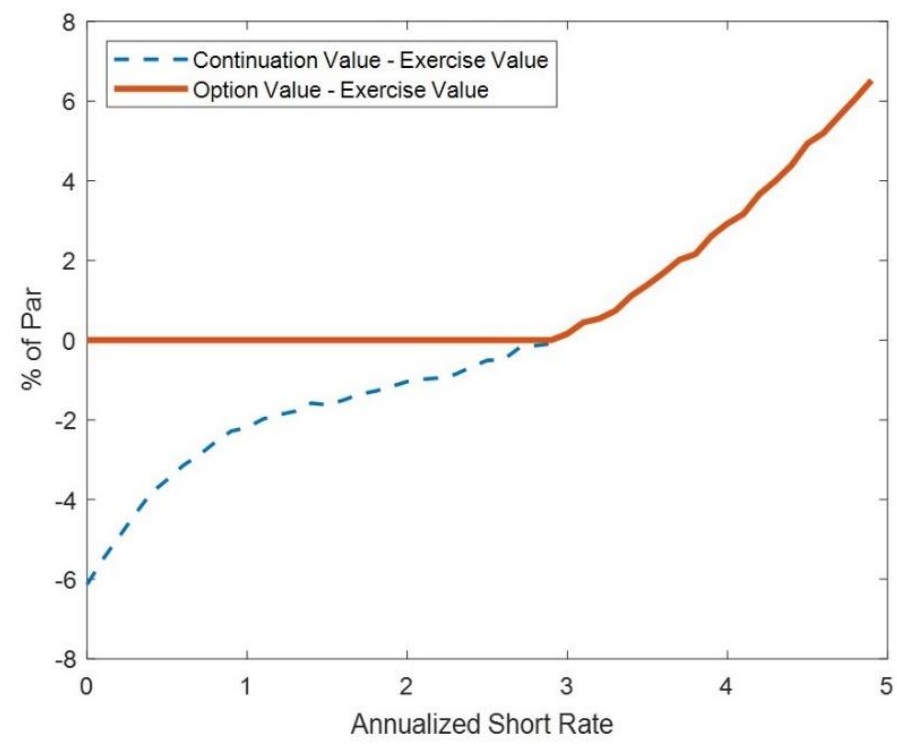

This figure describes a 10 year, semi-annual 5\% coupon bond that is currently callable. This plot shows the difference between continuation and exercise value (blue-dotted line) as well as the difference between option and exercise value (red line) as a function of the annualized current short rate. These estimates assume the one-factor model with semiannual volatility of $0.40 \%$ and a zero rate lower bound for the path of the short rate. 


\section{Figure B2. Model Implied Exercise Region}

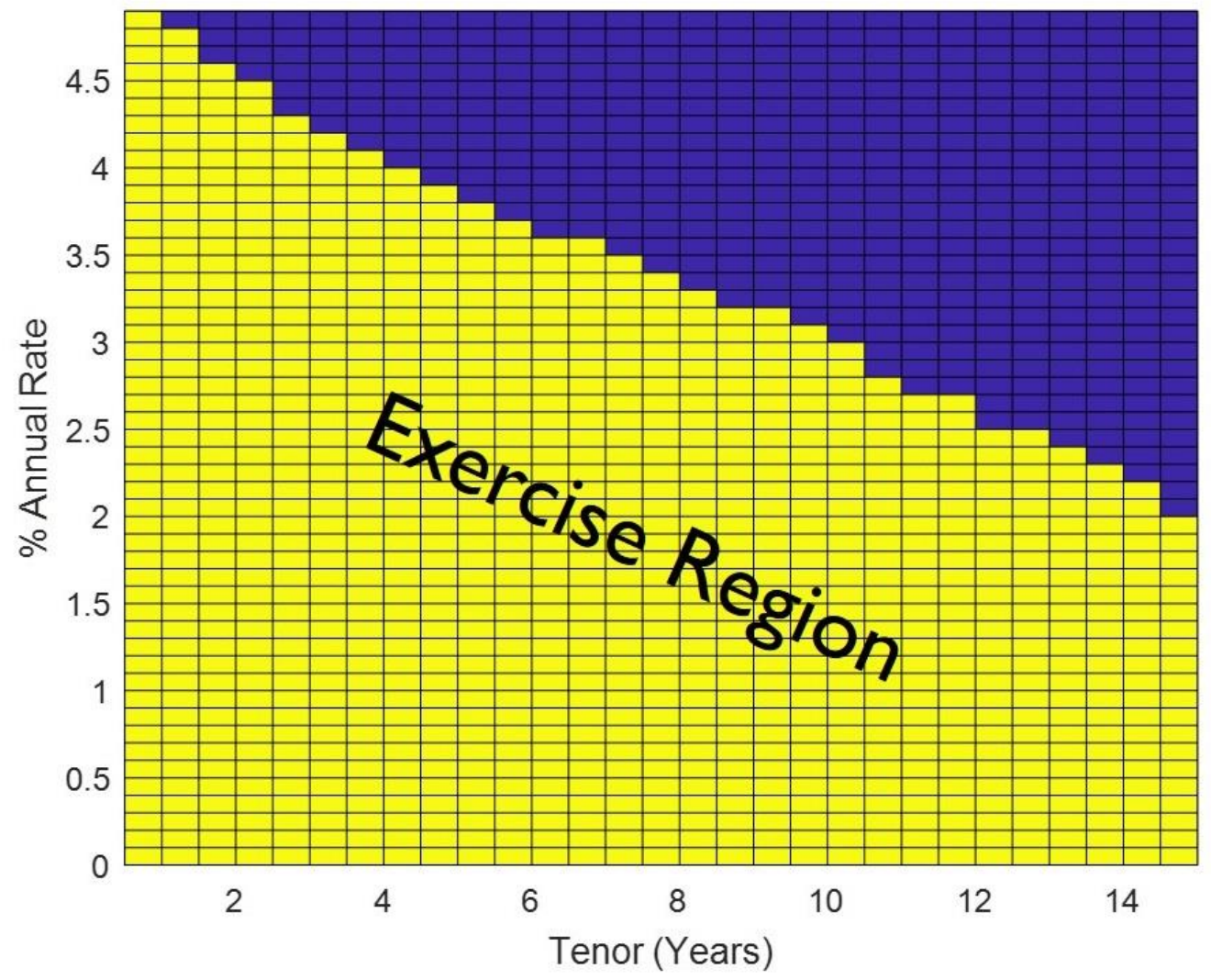

This figure plots the region in which a bond issuer should exercise its call option immediately after it is unlocked as a function of tenor (x-axis) and the current interest rate (y-axis). The blue region represents states in which the bond should wait to call, while the yellow region represents states in which the bond should exercise immediately. These estimates assume a semi-annual 5\% coupon and a Merton one-factor random walk model with semi-annual volatility of $0.40 \%$ and a zero rate lower bound. 


\section{Figure B3. Alternative Specification and Total Value Lost}

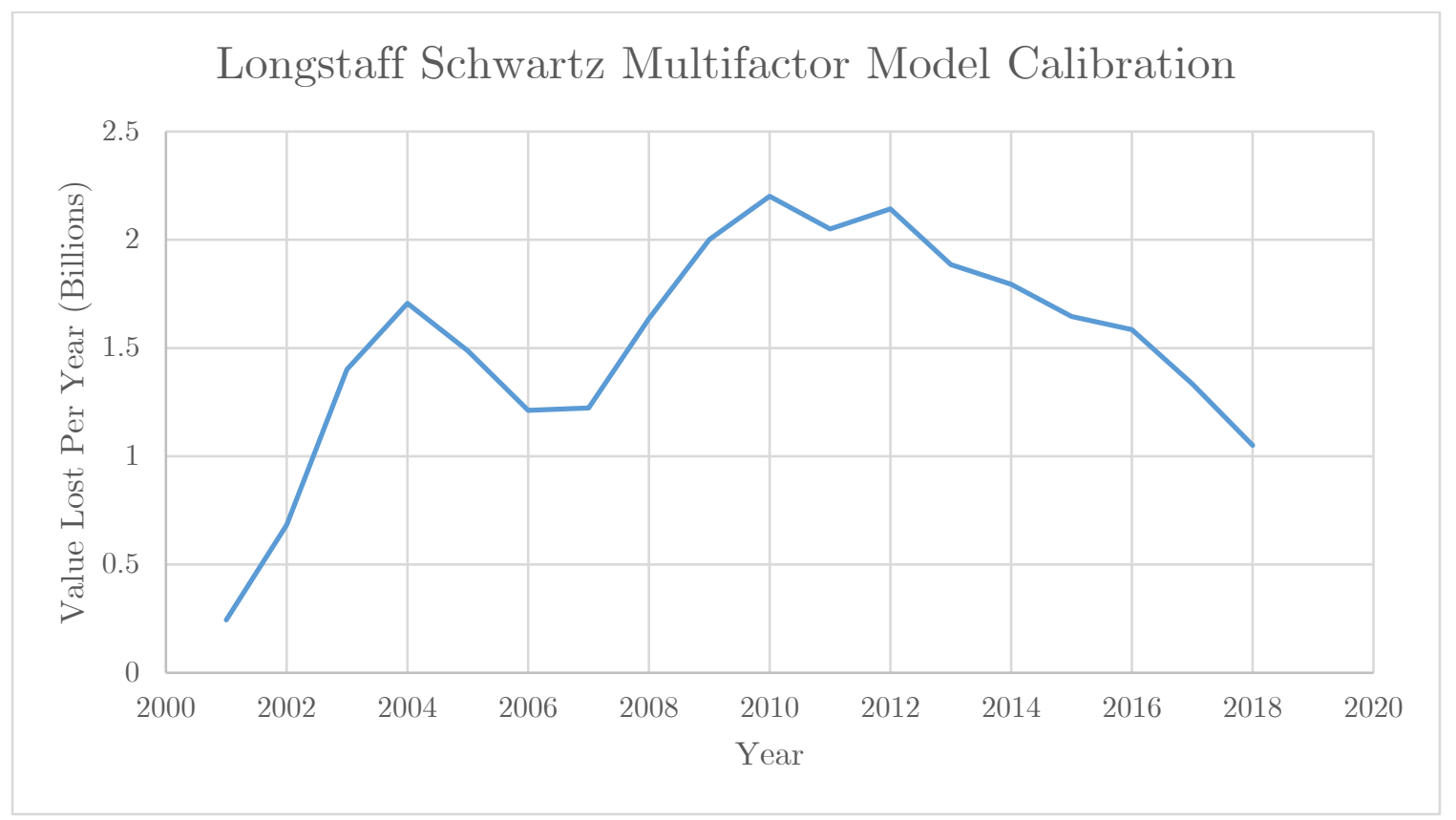

This figure calibrates the value lost per annum using the multifactor interest rate model of Longstaff and Schwartz (1992). The short-rate dynamic in the continuous model is:

$$
\begin{aligned}
& d r_{t}=\left(\mu X_{t}+\theta Y_{t}\right) d t+\sigma \sqrt{Y_{t}} d W_{1 t} \\
& d X_{t}=\left(a-b X_{t}\right) d t+c \sqrt{X_{t}} d W_{2 t} \\
& d Y_{t}=\left(d-e Y_{t}\right) d t+f \sqrt{Y_{t}} d W_{3 t}
\end{aligned}
$$

In the Euler-discretization, we follow the following specification:

$$
\begin{gathered}
r_{t}=r_{t-1}+\left(\mu X_{t}-b Y_{t}\right)+c \sqrt{Y_{t}} \epsilon_{1 t} \\
X_{t}=X_{t-1}+\left(a-b X_{t-1}\right)+c \sqrt{X_{t-1}} \epsilon_{2 t} \\
Y_{t}=Y_{t-1}+\left(d-e X_{t-1}\right)+f \sqrt{Y_{t-1}} \epsilon_{3 t}
\end{gathered}
$$

The calibrated parameters are chosen as:

$$
a=0.01, b=0.1, c=1, d=0.01, e=1, f=1, \mu=1, \theta=1, \sigma=1, X_{0}=0.01, Y_{0}=0.4
$$

The short rate is matched to concurrent market muni rates. 
Table B1. Summary Statistics on Exercise Value, Call Option Values as \% of Par.

\begin{tabular}{|c|c|c|c|c|c|c|}
\hline & Mean & $\begin{array}{l}\text { Standard } \\
\text { Deviation }\end{array}$ & Q1 & Median & Q3 & $\mathrm{N}$ \\
\hline $\begin{array}{l}\text { Exercise Value } \\
\text { (No Fee) }\end{array}$ & $11.437 \%$ & $7.427 \%$ & $5.647 \%$ & $10.321 \%$ & $15.887 \%$ & $1,477,279$ \\
\hline $\begin{array}{l}\text { Continuation } \\
\text { Value (No Fee) }\end{array}$ & $9.956 \%$ & $7.309 \%$ & $4.262 \%$ & $8.935 \%$ & $14.373 \%$ & $1,477,279$ \\
\hline $\begin{array}{l}\text { Value lost by a } 6 \\
\text { Months Delay } \\
\text { (No Fee) }\end{array}$ & $1.529 \%$ & $0.708 \%$ & $1.088 \%$ & $1.534 \%$ & $2.016 \%$ & $1,477,279$ \\
\hline $\begin{array}{l}\text { Exercise Value } \\
\text { (With Fees) } \\
\text { Continuation }\end{array}$ & $10.424 \%$ & $7.416 \%$ & $4.627 \%$ & $9.301 \%$ & $14.867 \%$ & $1,477,279$ \\
\hline $\begin{array}{l}\text { Value (With } \\
\text { Fees) } \\
\text { Value lost by a } 6\end{array}$ & $9.045 \%$ & $7.199 \%$ & $3.276 \%$ & $7.970 \%$ & $13.378 \%$ & $1,477,279$ \\
\hline $\begin{array}{l}\text { Months Delay } \\
\text { (With Fee) }\end{array}$ & $1.294 \%$ & $0.788 \%$ & $0.668 \%$ & $1.044 \%$ & $1.296 \%$ & $1,477,279$ \\
\hline
\end{tabular}

This table summarizes the exercise values, continuation values, and the 6-month delay value lost for each individual callable bond that were not called starting each year in our sample. The first 3 rows contain the baseline 1 -factor model implied exercise values, continuation values, and value lost. The last 3 rows contain same statistics for the 1 -factor model with $1.02 \%$ issuance fees. 


\section{Appendix C: Comparison of the Traded Prices of Corporate Bonds}

Examining municipal bonds' trading prices for optimal call executions is often not possible due to the infrequency of trading, especially for long-term outstanding bonds. However, corporate bonds do more frequently trade and have prices recorded in the TRACE database.

Following earlier methodology in King and Mauer (2000), in addition to our parametric value-lost calculations, we examine whether callable corporate bonds trade significantly above their call prices. The idea is that if investors trade these securities at high premiums to their call price, then there is value savings left unutilized by the issuer.

The below table shows an examination of this during our sample period of 2001 to 2018. Specifically, the monthly Volume Adjusted Price (VAP) minus the Call Price from Mergent FISD for currently callable corporate bonds with fixed call prices is reported below. We see that very few corporate bonds ever trade higher than their call price during this sample period. Even in these cases, the price deviation above the call price is typically less than their accumulated coupon interest. At the $95^{\text {th }}$ percentile, the VAP only exceed the trade price by less than $1 \%$ - an amount typically within the accumulated coupon interest.

\begin{tabular}{|l|l|l|l|l|l|l|l|}
\hline & Mean & Std & Q1 & Median & Q3 & $\begin{array}{l}95^{\text {th }} \\
\text { Percentile }\end{array}$ & N \\
\hline $\begin{array}{l}\text { Volume Adjusted Price } \\
\text { Minus Call Price for Call } \\
\text { at Par Bonds }\end{array}$ & $-13.018 \%$ & $22.480 \%$ & $-15.722 \%$ & $-3.541 \%$ & $-0.637 \%$ & $0.847 \%$ & 43,519 \\
\hline $\begin{array}{l}\text { Volume Adjusted Price } \\
\text { Minus Call Price for Call } \\
\text { above Par Bonds }\end{array}$ & $-25.282 \%$ & $34.398 \%$ & $-35.029 \%$ & $-7.313 \%$ & $-2.411 \%$ & $0.061 \%$ & 53,161 \\
\hline
\end{tabular}

For callable bonds without fixed call prices, we find that they are typically provisioned with "CC @ Make-Whole" indentures. That is the issuer has to pay the par value plus a calculated NPV of all the future coupon payments in order to redeem. These features exist in less than $2 \%$ of municipal bonds, but are extremely frequent in the corporate bond database- variable call price bonds are issued 5 times as often as fixed call price bonds.

The VAP of these bonds as summarized as follows.

\begin{tabular}{|l|l|l|l|l|l|l|l|}
\hline & Mean & Std & Q1 & Median & Q3 & $\begin{array}{l}95^{\text {th }} \\
\text { Percentile }\end{array}$ & N \\
\hline Volume Adjusted Price & $105.280 \%$ & $14.163 \%$ & $100.148 \%$ & $104.938 \%$ & $111.594 \%$ & $126.396 \%$ & 573,879 \\
\hline
\end{tabular}

